\title{
Review
}

Samrand Saeidi, Masoud Talebi Amiri, Nor Aishah Saidina Amin* and Mohammad Reza Rahimpour

\section{Progress in Reactors for High-Temperature Fischer-Tropsch Process: Determination Place of Intensifier Reactor Perspective}

\begin{abstract}
High-temperature Fischer-Tropsch (HTFT) process aims to produce lighter cuts such as gasoline and diesel. For many years there have been studies and improvements on HTFT process to make the existing reactors more efficient. Recent studies proposed new configurations such as dual-type membrane reactor and coupling configurations reactor, which improved the performances of this process. This achievement persuades us to update the existing knowledge about the available reactors for HTFT process. In this article, features and performances overview of two classes of reactors are reviewed. The first class consists of the reactors which are based on older studies, and the second one includes recent studies which are called product intensifier reactors. Finally, it is shown that the product intensifier reactors have higher CO conversions and lower selectivity of undesired by-products which results in higher production yield of gasoline. Furthermore, the place of product intensifier reactor among common reactors with regard to the influence of the process parameters on the product distribution has been estimated.
\end{abstract}

*Corresponding author: Nor Aishah Saidina Amin, Chemical Reaction Engineering Group, Faculty of Chemical Engineering, Universiti Teknologi Malaysia, UTM Skudai, 81310 Johor Bahru, E-mail: noraishah@cheme.utm.my

Samrand Saeidi, Chemical Reaction Engineering Group, Faculty of Chemical Engineering, Universiti Teknologi Malaysia, UTM Skudai, 81310 Johor Bahru, E-mail: samrandsaidi@gmail.com

Masoud Talebi Amiri, Swiss Federal Institute of Technology in Lausanne (EPFL), Lausanne, Switzerland, E-mail: masoud.talebiamiri@epfl.ch

Mohammad Reza Rahimpour, Department of Chemical Engineering, School of Chemical and Petroleum Engineering, Shiraz University, Shiraz 71345, IranE-mail: rahimpor@shirazu.ac.ir
Keywords: high temperature, Fischer-Tropsch process, intensifier reactors, $\mathrm{CO}$ conversions, gasoline production

DOI 10.1515/ijcre-2014-0045

\section{Introduction}

Gas-to-liquid processes of Fischer-Tropsch synthesis (FTS) attracted attention from academic and industrial interests, considering the growth rate in the international oil price [1]. FTS which converts synthesis gas $\left(\mathrm{CO}+\mathrm{H}_{2}\right)$ derived from coal or natural gas [2] or biomass complex multi-component mixture of linear and branched hydrocarbons and oxygenated products is a well-established technology $[3,4]$. Fischer-Tropsch (FT) plants are often classified in terms of feed material as coal-to-liquids [5], gas-to-liquids (GTL) [6], or biomass-to-liquids [7-13] plants; the feed material does not determine the type of FT technology or the product composition. The feed material has effect only on the gasifier type [14], and once the feed has been converted to synthesis gas, the gas loop can be configured to suit the FT technology. Figure 1 briefly presents the overall process of liquid fuel production by FTS [7].

The FTS is production of a range of products by catalytic hydrogenation of $\mathrm{CO}$. This range of products covers the production of high-quality diesel fuel, gasoline, and linear chemicals such as 1-alkenes, alkenes, and oxygenated hydrocarbons $[16,17]$. Table 1 exhibits the basic reactions in the FTS.

The FT reaction is highly exothermic, and the enthalpy change per mol of CO converted is about $165-180 \mathrm{~kJ} \mathrm{~mol}^{-1}$ (depends on the precise product composition). This enthalpy of reaction is much higher than for the processes which take place in the oil industry $[18,19]$. In consequence, all FT reactors are designed to maximize heat removal. Inadequate cooling system will result in lower selectivity of 


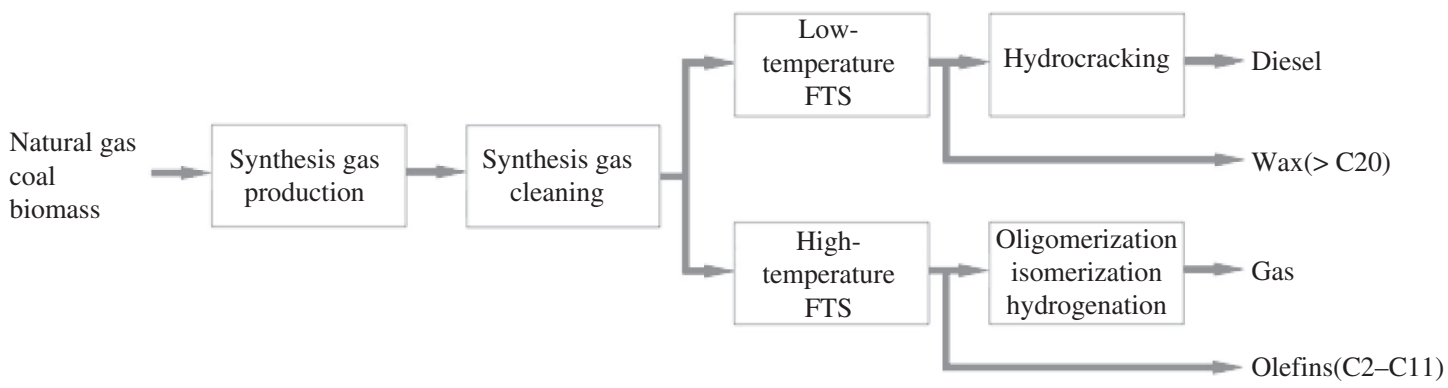

Figure 1 Overall process for production of fuels by FTS [15]

Table 1 Major overall reactions in the FTS [16]

\begin{tabular}{|c|c|}
\hline \multicolumn{2}{|l|}{ Main reactions } \\
\hline Paraffins & $(2 \mathrm{n}+1) \mathrm{H}_{2}+\mathrm{nCO} \rightarrow \mathrm{C}_{\mathrm{n}} \mathrm{H}_{2 \mathrm{n}+2}+\mathrm{nH}_{2} \mathrm{O}$ \\
\hline Olefins & $2 \mathrm{nH}_{2}+\mathrm{nCO} \rightarrow \mathrm{C}_{\mathrm{n}} \mathrm{H}_{2 \mathrm{n}}+\mathrm{nH}_{2} \mathrm{O}$ \\
\hline Water/gas shift reaction & $\mathrm{CO}+\mathrm{H}_{2} \mathrm{O} \leftrightarrow \mathrm{CO}_{2}+\mathrm{H}_{2}$ \\
\hline Alcohols & $2 \mathrm{nH}_{2}+\mathrm{nCO} \rightarrow \mathrm{C}_{\mathrm{n}} \mathrm{H}_{2 \mathrm{n}+2} \mathrm{O}+(\mathrm{n}-1) \mathrm{H}_{2} \mathrm{O}$ \\
\hline Boudouard reaction & $2 \mathrm{CO} \rightarrow \mathrm{C}+\mathrm{CO}_{2}$ \\
\hline \multicolumn{2}{|l|}{ Catalyst modifications } \\
\hline \multirow[t]{2}{*}{$\begin{array}{l}\text { Catalyst oxidation/ } \\
\text { reduction }\end{array}$} & $\mathrm{M}_{\mathrm{x}} \mathrm{O}_{\mathrm{y}}+\mathrm{yCO} \leftrightarrow \mathrm{yCO}{ }_{2}+\mathrm{xM}$ \\
\hline & $\mathrm{M}_{\mathrm{x}} \mathrm{O}_{\mathrm{y}}+\mathrm{yH}_{2} \leftrightarrow \mathrm{yH}_{2} \mathrm{O}+\mathrm{xM}$ \\
\hline Bulk carbide formation & $\mathrm{yC}+\mathrm{xM} \leftrightarrow \mathrm{M}_{\mathrm{x}} \mathrm{C}_{\mathrm{y}}$ \\
\hline
\end{tabular}

preferred products and higher catalyst deactivation and in the worst-case scenario may induce a runaway [19].

Hydrocarbon formation in the FT reaction is closely similar to polymerization kinetics in which hydrocarbons are formed by the addition of activated $C_{1}$ groups on the end of an absorbed growing hydrocarbon chain [19]. A mathematical expression which is used for describing hydrocarbon production is the Anderson-Schulz-Flory (ASF) distribution as:

$$
\operatorname{In}(\mathrm{Wn} / \mathrm{n})=n \ln (\alpha)+\ln ((1-\alpha) 2 / \alpha) ;
$$

where $\alpha=$ probability of chain growth, $\mathrm{Wn}=$ weight fraction of molecules with chain length, and $n=$ carbon number of chain length [15, 17]. Figure 2 provides a graphical representation of the ASF distribution [17, 20].

Several metals such as nickel, cobalt, ruthenium, and iron have been shown to be active for FTS. On a relative basis, among different metals capable of commercial applications for FT process if the scrap iron price is $1.0 \$$, then the costs of $\mathrm{Ni}, \mathrm{Co}$, and $\mathrm{Ru}$ are considered approximately 250 , 1000 and 50000 \$, respectively. Furthermore, Ni produces too much $\mathrm{CH}_{4}$ under practical operating conditions, and the amount of $\mathrm{Ru}$ is insufficient besides its high price. Therefore, only Fe and Co are practical catalysts for FT process [4] and appear to be economically feasible in an industrial scale. Iron-based catalyst is used in both high-temperature

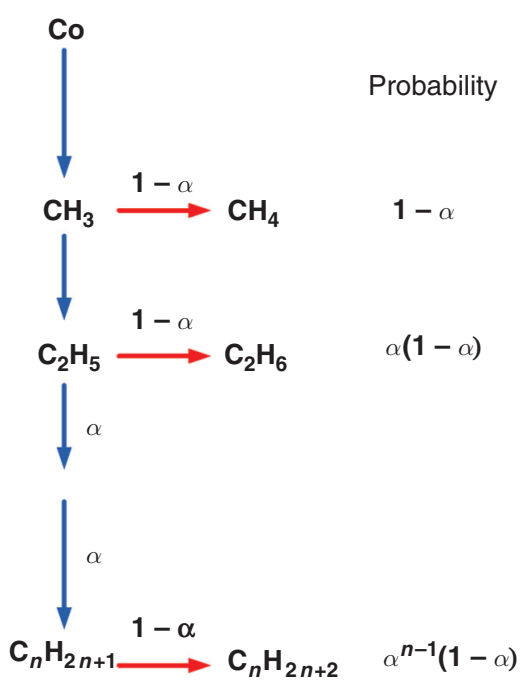

Figure 2 Probability of chain growth to different hydrocarbons in FT reactions [21]

Fischer-Tropsch (HTFT) and low-temperature FischerTropsch (LTFT), while cobalt based catalyst is used usually in LTFT. Moreover, Saeidi et al. [22] has proved that the effect of reactor configuration on hydrocarbon production efficiency is much more than the effect of catalyst type modifications and operating condition changes.

Guillou et al. [23] studied the reaction over a $\mathrm{Co} / \mathrm{SiO}_{2}$ catalyst in a wall-coated microreactor. Three points of non-uniform injection of $\mathrm{H}_{2}$ were introduced: $11 \%$ of $\mathrm{H}_{2}$ in the main injection, $22 \%$ in the second, and $66 \%$ in the third. The $\mathrm{C}_{1}-\mathrm{C}_{4}$ cut yields were halved without reducing the $\mathrm{C}_{5}^{+}$cut yield, which, even though a decrease in $\mathrm{CO}$ conversion was observed, lead to an improvement in the overall production and use of hydrogen. Rafiee and Hillestad [24] carried a simulation study over an ironbased catalyst. They optimized the hydrogen distribution over three membrane reactors in series in order to get a maximum wax production and carbon monoxide conversion. They concluded that with an inlet ratio of $\mathrm{H}_{2} / \mathrm{CO}$ of 0.5 and a continuous introduction of the rest of the hydrogen through the membrane reactors, increased 
selectivity toward heavy hydrocarbons and increased wax concentration could be obtained.

Florent Allain et al. [25] concentrated on the possibilities of investigation to shift an equilibrium reaction to maximize the conversion by reactant staging. The analytical expression of global conversion has been derived for a series of two continuously stirred-tank reactors. While in this research place of product intensifier reactor among common reactors with regard to the influence of the process parameters on the product distribution has been estimated.

As shown in Figure 1, there are two operating modes of natural gas production based on FT process technology which are called LTFT [26] and HTFT [4, 15]. Table 2 presents the practical information about these two operating modes (FT processes of Sasol). As it is shown in Table 2 and Figure 1, the high-temperature process with iron-based catalysts at temperature range of about 300$350^{\circ} \mathrm{C}$ is usually used to produce gas and linear low molecular mass olefins $\left(\mathrm{C}_{2}-\mathrm{C}_{11}\right)$ [6]. The product cuts and its distribution are not the case in this paper.

Table 2 General commercial information about LTFT and HTFT processes of Sasol [27]

\begin{tabular}{lll}
\hline FT process & LTFT & HTFT \\
\hline Temperature & $220-260^{\circ} \mathrm{C}$ & $320-350^{\circ} \mathrm{C}$ \\
Catalyst & $\mathrm{Fe} / \mathrm{Co}^{\mathrm{a}}$ & $\mathrm{Fe}$ \\
Traditional reactor & ARGE & Synthol \\
Type & Tubular & Circulating bed \\
Advanced reactor & Sasol Slurry-Phase & Sasol Advanced \\
& Distillate & Synthol \\
Type & Slurry (Three-phase) & Fluidized-bed \\
\hline
\end{tabular}

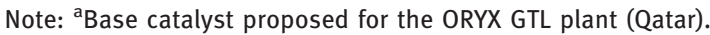

Indeed, reactor type is one of the most important factors affecting the products of FTS in both HTFT and LTFT technologies, therefore many studies have been performed on reactor types [22, 28]. In current research, most of these studies on reactor types merely in HTFT mode and their impacts have been collected from an open literature and discussed.

In this paper, the review of HTFT with focus on the reactors, and also, consequences of previous research in this field are evaluated. An extensive literature review to find the best reactor which could be obtained the high product conversion was compiled. The reactors were divided into two main categories of earlier reactors and recent ones. First the features and performances of earlier reactors are investigated, and their weaknesses for HTFT synthesis are discussed. Then the same study is done for product intensifier reactors which are recent innovative configurations [29-33]. Ultimately, results show that product intensifier reactor can be feasible and beneficial for achieving the renewable energy.

\subsection{High-temperature Fischer-Tropsch processes}

The high-temperature process with iron-based catalysts at temperature range of $300-350^{\circ} \mathrm{C}$ is mainly used to produce gasoline [34] and linear low molecular mass olefins. In HTFT, as a result of the process conditions and the catalysts involved, the produced syncrude includes a high percentage of short chain (i.e. $<10$ carbon atoms) with significant amounts of propane and butane mixed with olefins (e.g. propylene and butylene) which are extracted from the tail gas stream, utilizing cryogenic separation. Then, the resultant lean tail gas is recycled and mixed with additional lean feed gas for further syngas production [35].

The products of HTFT process are mostly fuels such as gasoline and diesel which are more closely to products of conventional oil refining. These produced GTL fuels are sulfur-free, but contain some aromatics [36]. Typical process operation conditions for HTFT are temperature of $\sim 320^{\circ} \mathrm{C}$ and pressure of $\sim 2.5 \mathrm{MPa}$ with conversion of $>85 \%$ [6], however not all the products are capable of producing high-quality transport fuels or usable. HTFT processes commonly take place in either circulating fluidized-bed (CFB) reactors or fluidized-bed reactors [37].

\subsection{Scope of the current review}

The main aim of this study is to review the existing literature regarding the reactor type for HTFT process owing to the reactor type which is one of the significant factors affecting the sustainable products. The fixed-bed and fluidized-bed as well as slurry-phase systems categorized as the common HTFT reactors which are appropriate for producing gas-phase products $[15,38,39]$. Besides these three reactor types for HTFT, the other configurations such as dual-type membrane reactors and coupling configuration reactors also have been investigated as product intensifier reactors [40-42]. This review first summarizes the evolution of coupling reactor types used for HTFT process and classification of different alternatives for HTFT process. For convenience, these data are brought in two tables. Thereafter, the new idea is to estimate the place of product intensifier reactor among common reactors with regard to the influence of the process parameters on the product distribution. 


\subsection{The evolution of HTFT reactors}

Considering the fact that the FT reactions are highly exothermic, to avoid overheating of the catalyst it is vital to remove the heat of reaction from the catalyst particles rapidly in an appropriate configuration; otherwise rate of deactivation increases due to sintering and fouling and also it may result in undesirable high production of methane. So, one of the main issues is selecting the reactor type and configuration $[4,15,43]$ which will be discussed in this article. Figures 3 and 4 indicate the trend of publications for HTFT reactors, the modern FT processes for production of liquid fuels. Figure 3 clarifies the amount of attention to the publications

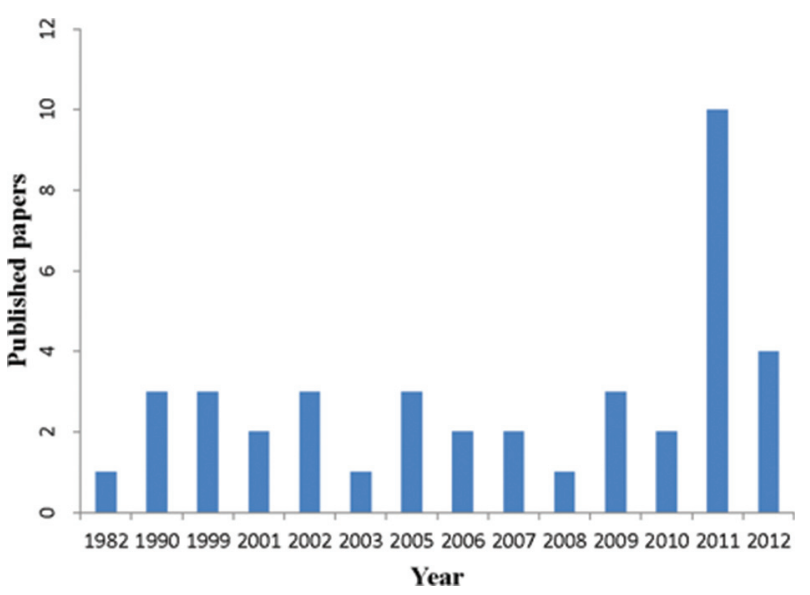

Figure 3 \% Published papers on HTFT reactors from 1982 to 2012

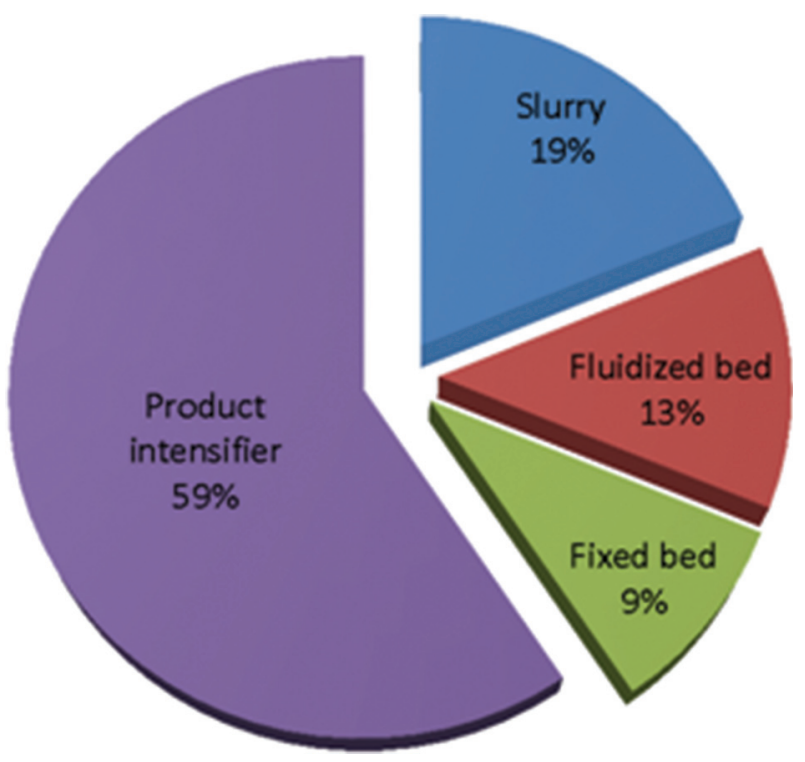

Figure 4 Distribution of published papers for each HTFT reactor from 1980 to 2012 related to HTFT reactors in the recent decade. Figure 4 also obviously shows that great attention has been paid to the product intensifiers as a new technology which is evolved recent years. Actually, the recent studies are mainly focusing on product intensifier reactors, and the researchers try to understand the behavior of these reactors better, in order to commercialize them. On the other hand, the main goal of the articles in earlier years was to investigate the fixed-bed, fluidized-bed, and slurry reactors as the available choices for FTS.

In this section, the outlook of experimental and theoretical research that has been done from 1982 to 2012 on each reactor type at high temperatures is presented. Despite there is a large number of publications through this period, there is not the opportunity to describe all papers. Therefore, the more important papers published in this period have been mentioned here.

The first category of reactors is the configurations that have been utilized very early and have been commercialized many years ago. This is the main reason that there are not enough tendencies for the researchers to study the different features and performances of these kinds of reactors.

In contrast, there is another scenario for the second category. They are new configurations such as combination of two different types of reactors which are invented recently. There is a huge interest from the researchers to study the different aspects and performances of these reactors as they are more flexible to manipulate and invent new configurations.

\section{HTFT reactor type and developments}

In principle, different reactor technologies are suitable for performing the highly exothermic FTS. Several of these concepts have been proven on laboratory, pilot plant, and industrial scale [44, 45].

Although, in general, the reactors are characterized based on their catalysts mode i.e. if the catalyst is fixed in the reactor it is called fixed-bed reactor, the other way to characterize the FTS is based on the temperature range in which these reactors operate. Different types of reactor configurations and their suitable working conditions are illustrated in Figure 5. When the temperature is increased to produce low boiling products, the appropriate reactor is the fluidized-bed reactor, and in order to achieve high boiling products with decreasing temperature, the fixedbed reactors and slurry-phase reactors are the choices. At 


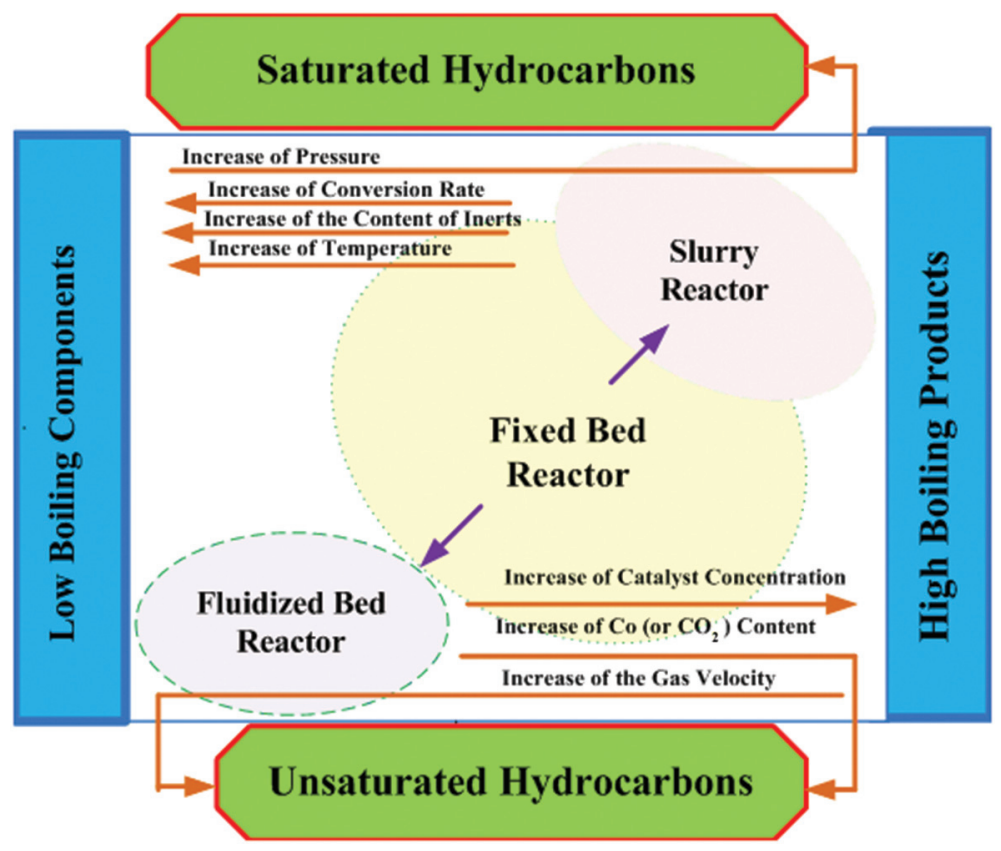

Figure 5 Influence of the process parameters in the different types of reactor on the product distribution [46]

high temperatures, in order to intensify the products, other reactors such as dual, membrane as well as coupling loop reactors can be placed between fixed-bed and fluidized-bed reactors.

At the end of this article, an updated version of the diagram shown in Figure 5 will be presented to express the effect of different parameters such as pressure, temperature, feed ratio, the content of inert, catalyst concentration, and gas velocity on the performances of reactors including product intensifier reactors. For slurry reactor, we should increase the parameters such as temperature, pressure, and feed ratio to produce gasoline, and for fluidized-bed reactor which is naturally utilized for producing gasoline, we have to increase some parameters such as catalyst concentration, gas velocity while reducing other parameters such as temperature, pressure, and feed ratio to produce wax. Finally, it should be taken into consideration that fixedbed reactor stands in between these two reactors; therefore, it functions in a wide range of the parameters.

\subsection{Fixed-bed reactors}

The first industrial fixed-bed reactor was Ruhrchemie atmospheric fixed-bed reactor (1935). This reactor consisted of a box divided into sections by vertical metal sheets and horizontal cooling tubes crossing the sheets. The place between sheets and tubes was for loading the catalyst [47, 48].
The most important feature of fixed-bed reactors is that there is no need to another section for catalyst separation. It is also easier to scale up these reactors from a tube in laboratory scale to a pilot plant. These facts made fixedbed reactors very interesting for FTS [49].

The general configuration of fixed-bed reactor consists of a long steel tube with a desired diameter. This tube is covered with a steel jacket containing high-pressure dowtherm. The electrical heating elements around the jacket provide the required energy for heating the dowtherm. Different temperatures of the jacket are satisfied by boiling the dowtherm under different pressures. Due to the circulation of the dowtherm, the temperature will be constant along the length of the reactor. For each experiment, the reactor tubes will be filled partially with catalyst from the bottom to the top. This is also a preheating section which supplies the preheating energy for the reacting mixture. Thermocouples are placed in the packing through the tips located at the center of the tube and specified apart along the length of reactor [50].

The conventional fixed-bed reactors may face some problems for removing the produced heat by FTS reaction. The best practical solution to this problem is to use a couple of tubes instead of a single tube and install the cooling system between them. This configuration is named multi-tubular reactor. For further explanation, this reactor consists of a multi-tube reactor which has the bed of catalyst inside the tube, and the syngas enters the reactor from the top. The syngas flow is in plug-flow 


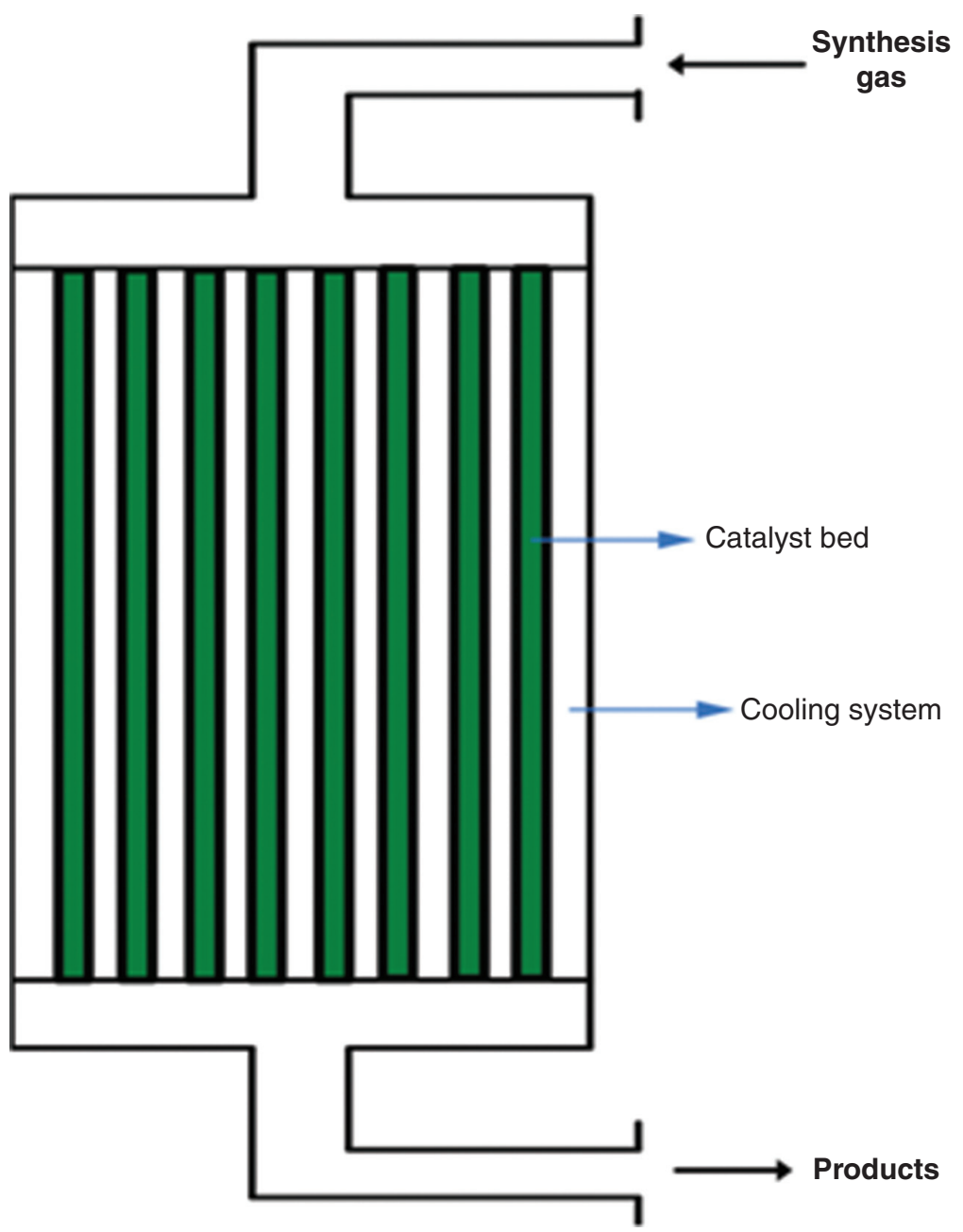

Figure 6 Multi-tubular fixed-bed reactor

regime. Simultaneously, water is circulating in the shell side of the reactor to maintain the temperature of the reactor constant and satisfy the isothermal condition. In fact, water will remove the produced heat by FTS reaction [51]. Configuration of a multi-tubular fixed-bed reactor is shown in Figure 6 [15].

As the main goal of HTFTS is to produce lighter cuts such as gasoline, there are good enhancement on these reactors to produce diesel, kerosene, and gasoline. Considering the high selectivity of the catalyst toward this cut, the amount of wax in the final product is decreased to zero. On the other hand, the production of light gasses should be as low as possible leading to highest possible production of transportation fuels. So one of the most important steps in FTS for production of diesel and gasoline is to reduce the amount of heavy hydrocarbons to enhance the production of desired cut which is transportation fuels [52].
Pellegrini et al. [53] as the result of their model concluded that increase in temperature has a positive effect on hydrocracking. In fact, due to the kinetic of the reactions, it will proceed more quickly. The heaviest lump is more sensitive to temperature changes, since it presents higher cracking activation energy, while in lighter lumps cracking products come mainly from heavier lumps.

On the other hand, the impact of pressure on the reaction is not significant. A high pressure works against dehydrogenation of paraffin and consequently for isomerization and cracking. The other point that they conclude is that the ratio of $\mathrm{H}_{2}$ /wax does not affect kinetics but it affects the condition of liquid-vapor equilibrium in the mixture which is very important for product distribution. A high quantity of hydrogen increases the degree of vaporization and causes a higher concentration in the liquid phase of the heaviest species, which are more reactive [53]. 
In 2005, Marvast et al. [54] modeled a fixed-bed reactor for FTS with Fe-HZSM5 catalyst. They also studied the parameters which have effect on the reactor performance. The configuration of the reactor is a water-cooled fixed-bed FT reactor packed with Fe-HZSM5 catalyst modeled in two dimensions (radial and axial).

Based on these parameters, finally they suggested the optimized operating condition to produce high octane gasoline from syngas. Result of the parametric sensitivity analysis is very interesting. Increasing the temperature in FTS reaction leads to an increase in the released heat of reaction. This fact means that the system will face temperature runaway. Increasing the temperature is also not recommended, considering gasoline and $\mathrm{CO}_{2}$ production rate. These two points express that fixed-bed reactors will face problems by increasing the temperature. In other words, although fixed-bed reactors are suitable reactors for LTFT synthesis, but they will show low performances for HTFTS reaction. It is also reported that the increase in the $\mathrm{H}_{2} / \mathrm{CO}$ ratio in the feed is not favorable for the gasoline production yield. The optimized $\mathrm{H}_{2} / \mathrm{CO}$ ratio for the reactor with this configuration is decided to be 0.8 . The results for the optimum working conditions are shown in Table 3 [54].

In 2011, Khadzhiev et al. [55] reported performances of a fixed-bed reactor for HTFT during their experiments. In a fixed-bed reactor under $30.1 \mathrm{bar}$ and $573 \mathrm{~K}$, the conversion of $\mathrm{CO}$ on the commercial catalyst was $60 \%$, and the selectivity for liquid hydrocarbons $\left(\mathrm{S}_{\mathrm{C}_{5}}^{+}\right)$was $66 \%$. The yield of liquid hydrocarbons was $68 \mathrm{~g} / \mathrm{m}^{3}$ [55].

Due to the fixed-bed reactor configuration and characteristics, this kind of reactors are more used for LTFT synthesis. Considering this point, researchers do not consider fixed-bed reactors and their performances as their main goal of study. This configuration, which is called conventional reactor (CR), is mostly used to compare the performances between different configurations. As a result, there are several articles that used the results from a fixed-bed reactor which was a pilot plant, for validation of their modeling and comparison of their results.

For instance, Rahimpour et al. in 2011 [56] reported a working condition and performances of a pilot plant which was a fixed-bed configuration. The scheme of the reactor which is reported as CR is shown in Figure 7.

This reactor is working under 17-bar pressure and the feed temperature of $565 \mathrm{~K}$. Considering this working condition, the CO conversion is reported $77.94 \%$ and the gasoline production yield is $700 \mathrm{~g} / \mathrm{g}$ feed. It is also reported that the highest temperature reached inside the reactor is $578 \mathrm{~K}$ considering the temperature profile [56]. In Table 3, the reported working condition and performances for fixed-bed reactors are shown.

Considering L.C.A. Mazzone simulation in 2006, the $\mathrm{H}_{2} / \mathrm{CO}$ ratio for the optimum operating condition in order to reach higher production yield of heavy olefins is between 1.45 and 1.75 . On the other hand, to maximize

Table 3 Summary of some experimental reports on CO conversion values based fixed-bed, fluidized-bed, and slurry bubble column reactors for a few selected results

\begin{tabular}{|c|c|c|c|c|c|c|c|}
\hline Number & Reactor & Catalyst & Temp. (K) & Press. (bar) & $\mathrm{H}_{2} / \mathrm{CO}$ in feed & CO conversion & Reference \\
\hline \multicolumn{8}{|l|}{ Fixed-bed } \\
\hline 1 & Fixed-bed & Fe-HZSM5 & 600 & 18 & 1.08 & $X_{C O}=92.8 \%$ & [54] \\
\hline 2 & Fixed-bed & $\mathrm{Fe}-\mathrm{Cu}$ & 573 & 30.1 & 2 & $X_{C O}=60 \%$ & [55] \\
\hline 3 & Fixed-bed & Fe-HZSM5 & 578 & 17 & 0.96 & $\mathrm{X}_{\mathrm{CO}}=78 \%$ & [56] \\
\hline 4 & Fixed-bed & Pt-Silica Alumina & 674 & 47.5 & $\begin{array}{l}\text { H2/wax } \\
=0.105\end{array}$ & $\begin{array}{r}\text { Gasoline in product } \\
=10 \% \mathrm{wt} / \mathrm{wt}\end{array}$ & [53] \\
\hline \multicolumn{8}{|c|}{ Fluidized-bed } \\
\hline 1 & Fluidized-bed & Fe-based & 543 & 10 & 1.6 & $\begin{array}{r}\text { Gasoline yield } \\
=0.148\end{array}$ & [60] \\
\hline 2 & Fluidized-bed & Fe-based & 553 & 20.5 & 0.67 & $X_{C O}=83.65 \%$ & [62] \\
\hline 3 & Fluidized-bed & Fe-based & 553 & 19.9 & 0.67 & $\mathrm{X}_{\mathrm{CO}}=78.07 \%$ & [62] \\
\hline 4 & Fluidized-bed & Fe-based & 543 & 20 & 0.67 & $X_{C O}=74.13 \%$ & [62] \\
\hline \multicolumn{8}{|c|}{ Slurry bubble column } \\
\hline 1 & Slurry & $\mathrm{Fe}$ & 563 & 30 & 1.5 & $\mathrm{X}_{\mathrm{CO}+\mathrm{H} 2}=97 \%$ & [67] \\
\hline 2 & Slurry & $\mathrm{Fe}-\mathrm{Mn}$ & 573 & 20 & 1.5 & $\mathrm{X}_{\mathrm{CO}}=76 \%$ & [68] \\
\hline 3 & Slurry & $\mathrm{Fe}-\mathrm{Cu}$ & 573 & 30.1 & 2 & $X_{C O}=61 \%$ & [55] \\
\hline
\end{tabular}




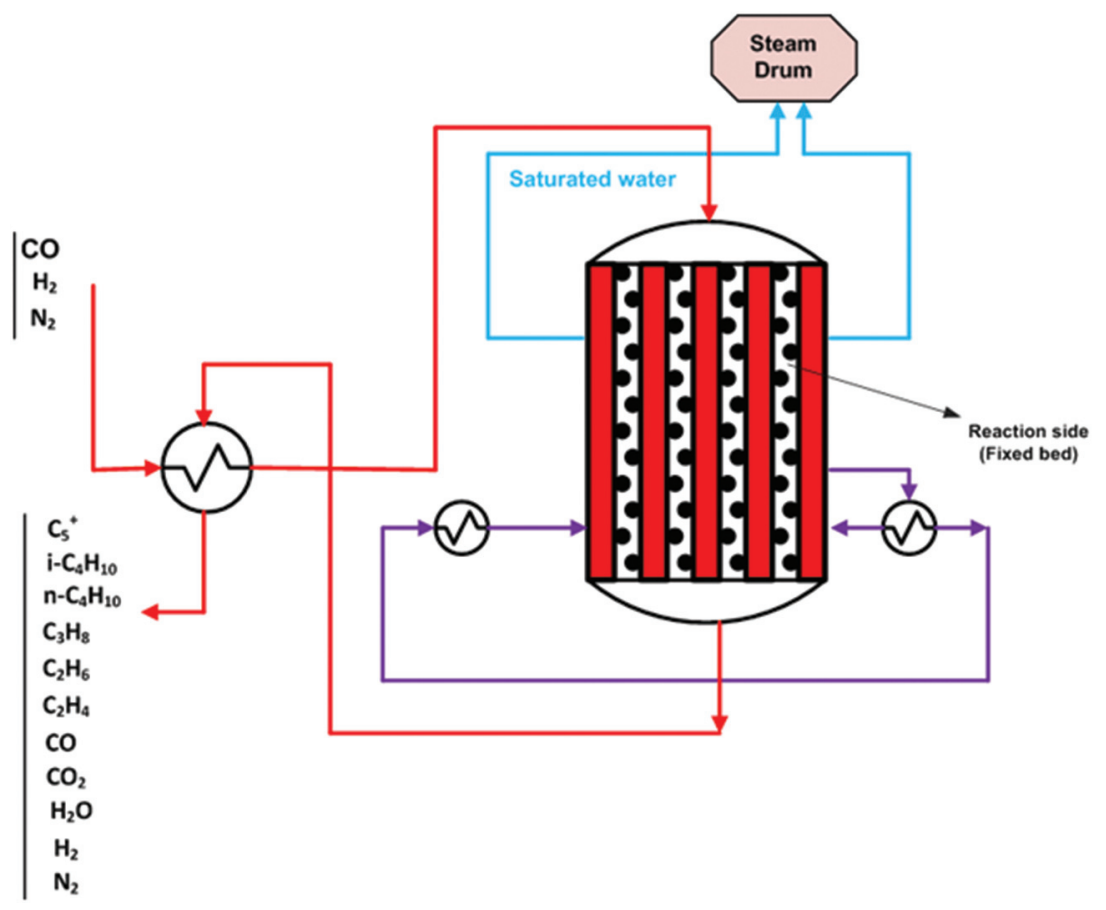

Figure 7 Multi-tubular reactor (CR)

the production yield of the light olefins, this ratio should be between 0.50 and 0.90 . Yields are lower than $5 \%$ in mass weight, in this configuration. For some commercialized catalysts the yields are higher than $15 \%$ in mass weight. It means that using this type of iron-based catalyst is not economically viable [51].

Rafiq et al. in 2011 studied fixed-bed reactor with a model bio-syngas at different gas hour space velocities (GHSVs). Results show that the $\mathrm{CO}$ and $\mathrm{H}_{2}$ conversion reached a maximum at lower GHSV. Selectivity of $\mathrm{C}_{1}-\mathrm{C}_{4}$ decreased, while $\mathrm{C}_{5}^{+}$selectivity and productivity of $\mathrm{HCs}$ increased with an increase in the GHSV. This modeling was also performed, and the obtained results from the simulation were validated with the experimental work. At last, parametric sensitivity analysis specified the impact of different parameters and developed a good understanding of the behavior of the fixed-bed FTS system. They also showed that an increase in the temperature of wall increases the $\mathrm{CO}$ and $\mathrm{H}_{2}$ conversion and $\mathrm{C}_{5}^{+}$ productivity in a continuous manner, but a momentous increase in the $\mathrm{CH}_{4}$ productivity was observed. However, upon increasing the wall temperature, the temperature runaway in the system was occurred most likely due to the release of extensive heat of reaction from the FTS [49].

Fernandes and Teles in 2007 [52] proved that lower temperatures $(550 \mathrm{~K})$ satisfy the cracking into diesel and higher temperatures $(650 \mathrm{~K})$ accomplish a better cracking to produce higher amounts of gasoline. To produce lighter cuts, they proposed to use several reactors in series but with different working conditions [52].

\subsection{Fluidized-bed reactors}

Fluidized-bed reactors are used in many chemical processes especially the processes involve gas-solid and solid-catalyzed gas-phase reactions [57]. There are a lot of examples for industrial applications of these reactors such as catalytic cracking of hydrocarbons, coal gasification, ore roasting, and synthesis reactions like FTS $[58,59]$.

The fluidized-bed reactor in FTS includes two different phases. Synthesis gas and inert gases enter the bottom of the reactor through a distributor, and then split to form the bubble and the emulsion phases. There is no need to excess gas to maintain the minimum fluidization condition. The remaining gases, which are non-reacted, exit from the top of the reactor through a disengaging zone. The diameter of this zone is usually larger than the catalytic bed zone. This difference in the diameter is for gas velocity reduction and facilitating the settling of catalyst particles. A reactor cyclone will separate the particles that pass through the disengaging zone from the gas 
phase and afterward they will be returned to the fluidized-bed reactor. These returned particles normally enter from near the top of the reactor. While the process is running, hydrocarbons are continuously formed and non-reacted syngas removes the product from the reactor. Cooling tubes are provided in the reactor for heat removal and to control the temperature, maintaining the isothermal conditions, despite the high heat of reaction [60].

CFB reactors were the choice for the first Sasol plant at Sasolburg that is shown in Figure 8. This reactor worked under the pressure of about $2 \mathrm{MPa}$ and temperature of $340^{\circ} \mathrm{C}$. After some time, optimizations on the process and improvement on the catalyst made this configuration well suited for this process, and they operated for many years. The improved reactors were named Synthol reactors. There are two phases of fluidized catalyst in a CFB reactor. Catalyst moves down the standpipe in dense phase, while it is transported up the "reaction" zone in lean phase [4].
The commercial FT reactors in the Brownsville, TX plant, which only operated for a brief period, were of the fixed fluidized-bed (FFB), and it is shown in Figure 9. FFB reactors operated under $2 \mathrm{MPa}$ and $300^{\circ} \mathrm{C}$ same larger type of CFB reactors [37].

To avoid the feed gas going up the standpipe, the differential pressure over the standpipe must always exceed that over the reaction zone. At the high operating temperature, carbon is deposited on the iron-based catalyst which decreases the bulk density of the catalyst and the differential pressure over the standpipe. It is therefore not possible to raise the catalyst loading in the reaction section in order to compensate for the normal decline of catalyst activity with time-on-stream. The main advantages of FFB over CFB reactors are as follows:

- The construction cost is $40 \%$ lower. For the same capacity the FFB reactor is much smaller in overall.

- Because of the wider reaction section more cooling coils can be installed to increase its capacity. (More

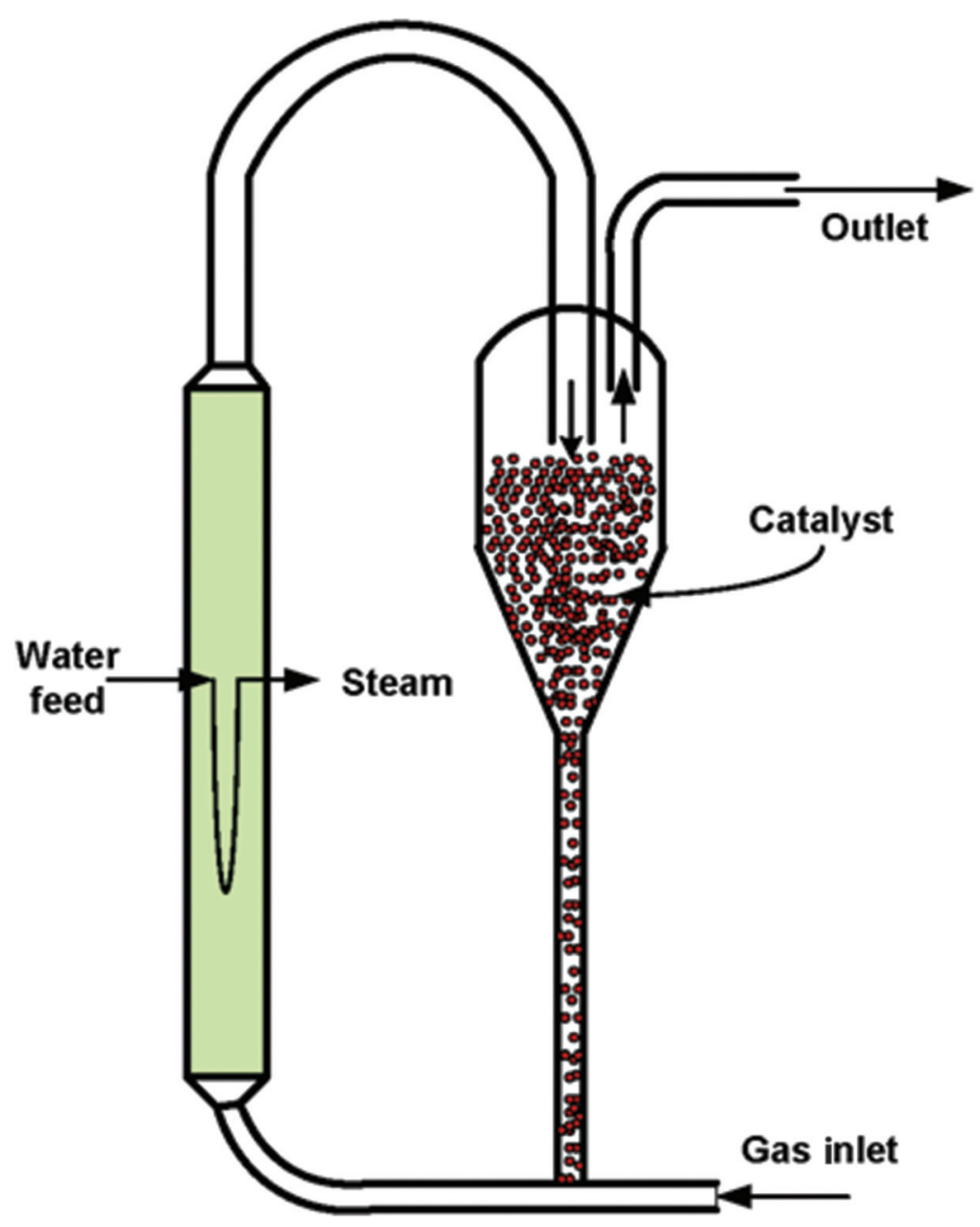

Figure 8 A CFB reactor 


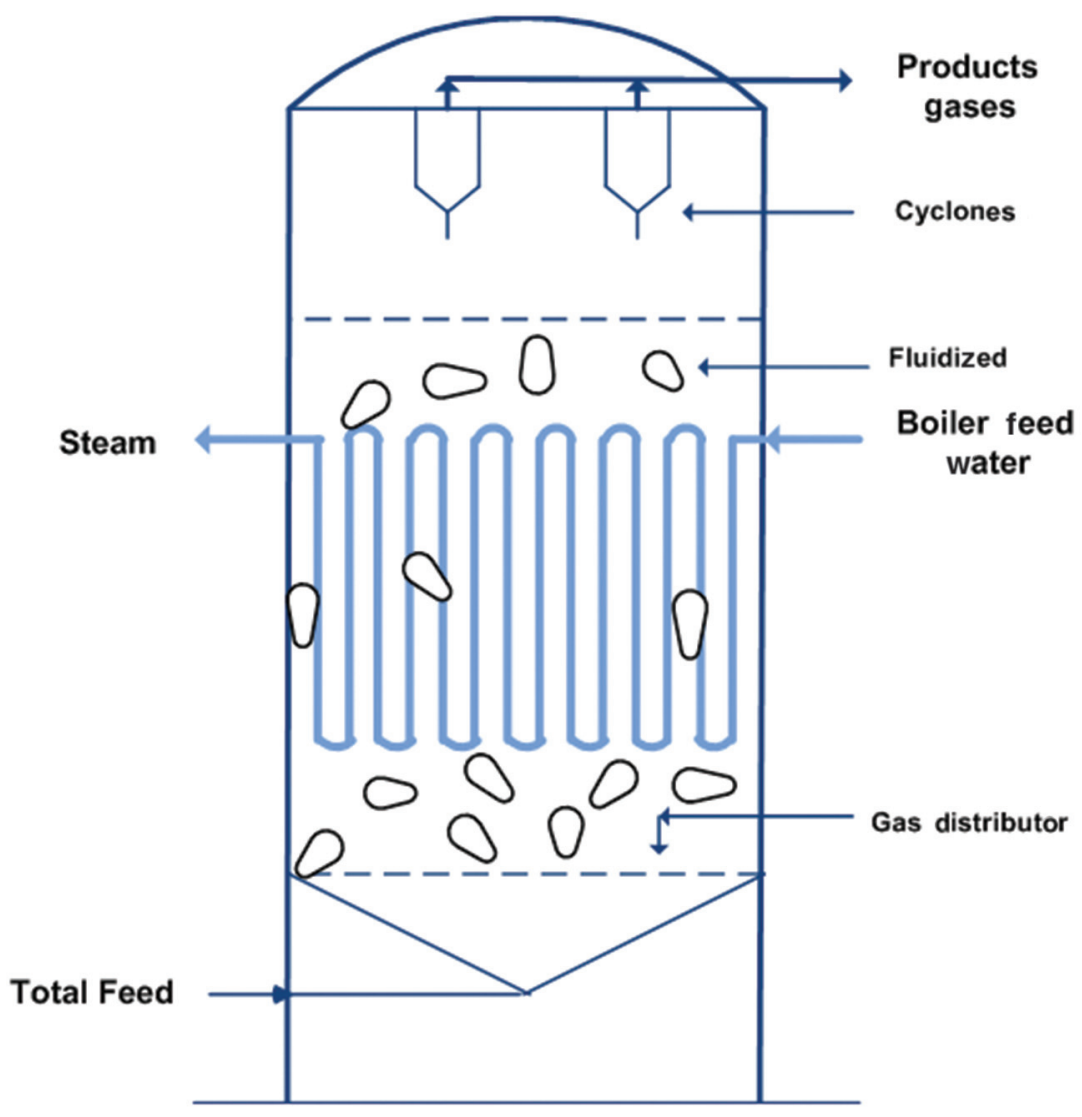

Figure 9 FFB reactor configuration

fresh gas can be fed by either increasing the volumetric flow or increasing the operating pressure. Pressures up to $4 \mathrm{MPa}$ are feasible.)

- At any moment all of the catalyst charge participates in the reaction, whereas in the CFB only a portion of it does.

- $\quad$ For the reasons previously discussed, the decrease in the bulk density by carbon deposition is of less significance in the FFB and thus a lower rate of on-line catalyst removal and replacement with fresh catalyst is required to maintain high conversions. This lowers the overall catalyst consumption.

- Because the iron carbide catalyst is very abrasive and the gas/catalyst linear velocities in the narrower sections of the CFB reactors are very high, these sections are ceramic lined and regular maintenance is essential. This problem is absent in the lower linear velocity FFB reactors, and this allows longer on-stream times between maintenance inspections [4].

Fernandes [61] developed a mathematical model of a fluidized-bed reactor which was used for polymerization of syngas. They studied the carbon monoxide polymerization with this model. For maximizing the diesel production yield, the optimum operating condition must be under low catalyst load, high pressure, and lowsuperficial gas velocity, but for maximum gasoline production yield, high catalyst load, and low pressure is needed. High $\mathrm{H}_{2}: \mathrm{CO}$ ratios favor production of low molecular weight products as gasoline, while low $\mathrm{H}_{2}$ : $\mathrm{CO}$ ratios deviate production toward heavy hydrocarbons, such as diesel [60].

In 2012, Mohammad Kazemeini et al. [62] studied the impact of different process condition parameters on FTS in fluidized-bed reactors. Their investigations show that the increase in the temperature will increase the CO conversion. The increase in the pressure of the process also favors the higher CO conversions. At last, they presented the optimum condition for highest reached CO conversion which is $83.65 \%$. The condition and results are shown in Table 3 [62].

The disadvantage of a fluidized system is that if any catalyst poison such as $\mathrm{H}_{2} \mathrm{~S}$ enters the reactor; all of the catalyst is deactivated, whereas in a fixed-bed reactor all 
the $\mathrm{H}_{2} \mathrm{~S}$ is adsorbed by the top layers of catalyst, leaving the rest of the bed unscathed [4].

\subsection{Slurry bubble column reactors}

The slurry bubble column reactors and its applications studied in by different researchers. Sasol R\&D proved that the selectivities and conversions of slurry and fixed-bed reactors are almost the same. In 1993, a 5-m i.d. commercial unit was designed and its capacity is about $100 \times 103 \mathrm{t} /$ year which equals that of the combined production of the original five ARGE reactors. Scheme of a slurry bubble column reactor is shown in Figure 10.

The advantages of slurry over multi-tubular reactors are as follows:

- The cost of a reactor train is only $25 \%$ of that for a multi-tubular system.

- The differential pressure over the reactor is about four times lower which results in lower gas compression costs (low pressure drop).
- The lower catalyst loading translates into fourfold lower catalyst consumption per tonne of product.

- The slurry bed is more isothermal and so can operate at a higher average temperature resulting in higher conversions.

- On-line removal/addition of catalyst allows longer reactor runs.

- Small solid particle size results in good productivity [4].

In a slurry bubble column, at relative low gas velocities, the homogeneous flow regime dominates. Synthesis gas enters and is distributed from the bottom. Carbon monoxide and hydrogen dissolve into the liquid phase as the gas passes through the suspension of catalyst and liquid products $[63,64]$. Then, the reaction takes place on the catalyst surface. In the homogeneous flow regime the gas phase consists of small bubbles, typically smaller than 5 $\mathrm{mm}$. Liquid products and catalyst exit from the top. On the other hand, the fresh catalyst enters the reactor at the bottom. It means that the reactor is in a co-current mode with respect to slurry and gas. The counter-current operation is not recommended because of the high degree of

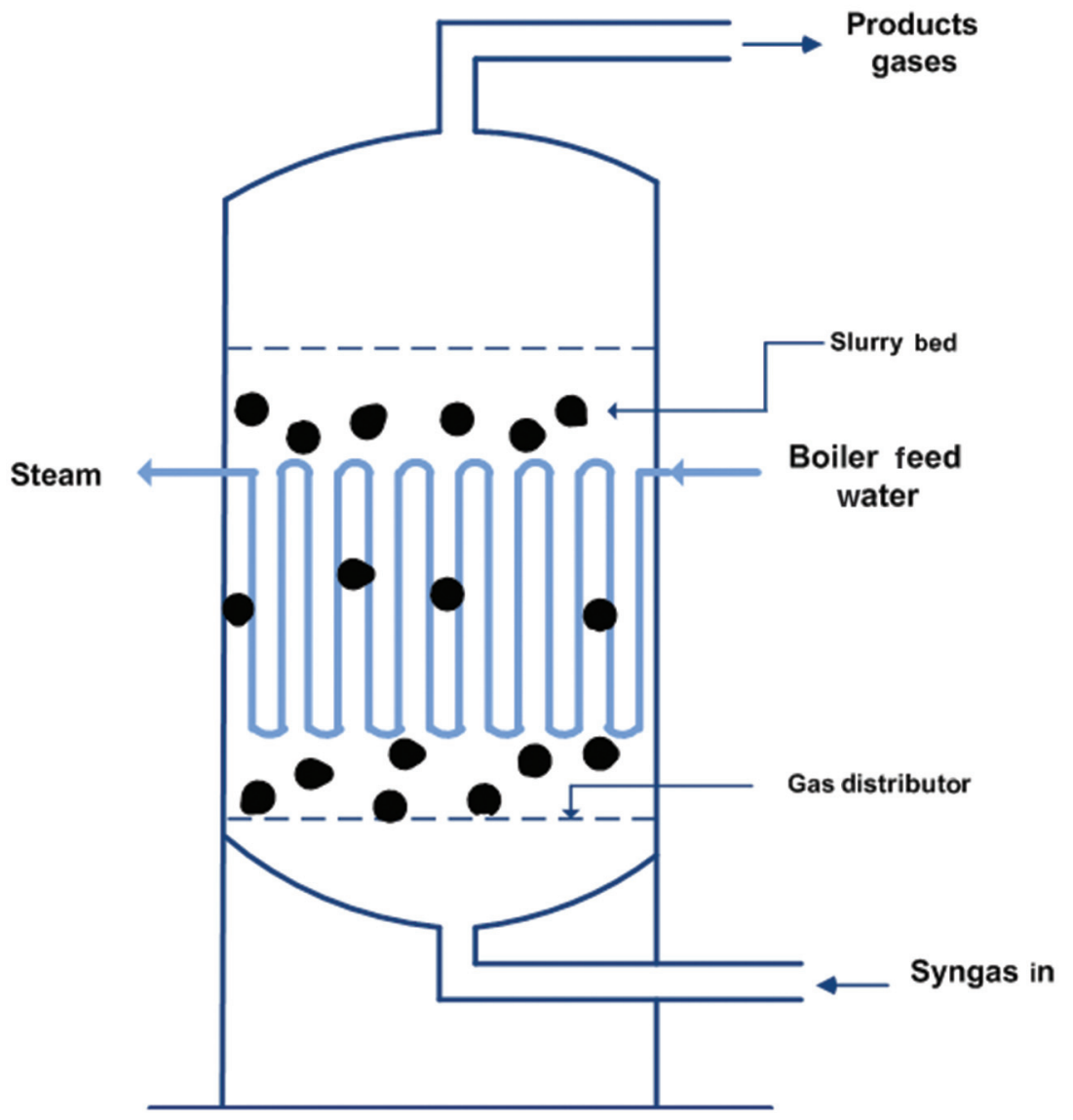

Figure 10 Slurry bubble column reactor 
back mixing in the slurry phase. However, the co-current operation avoids catalyst settling tendencies, which may result in serious heat transfer problems (hot spots). The cooling tubes remove the heat produced by the synthesis reaction [65].

At higher gas velocities, this is the churn-turbulent flow regime prevails in slurry bubble column reactors. The gas enters the bottom of the reactor and then it is divided into two parts: a part of the gas pass through the reactor in the form of large bubbles and the remaining are in the form of small bubbles. The large bubbles rise with a high velocity through the slurry (their rise velocity can easily exceed $1 \mathrm{~m} / \mathrm{s}$ ). Considering this fact, large bubbles impel circulation patterns in the suspension of liquid and catalyst. These circulation patterns severely mix up the small bubble population. Catalyst feed, liquid products removing, and reactor heat removal are the same as what was discussed in the homogeneous case [66].

Deckwer et al. [67] presented a modeling of a threephase reactor system exhibited by the description of the FTS in a slurry phase. The relevant reactors are only bubble agitated, and their length to diameter ratios are in the range of $5-10$. As the FTS in the slurry phase is accomplished in the slow reaction regime of mass transfer with reaction theory, the space-time-yield reaches a maximum value depended on the gas velocity. Calculations are based on the rate data of the Rheinpreussen-Koppers plant yield. As a result that the production capacity of the Sasol I1 plant could be achieved in only 11 slurry reactors of 5-m diameter and 14-m height. For isothermic conditions, the pressure of the reactor does not have effect on the conversion. If the reactor operates under non-isothermic conditions, the temperature rises and this makes the conversion to increase.

They studied the effect of different parameters on the performance of the reactor. The results show that an increase in temperature from 531 to $563 \mathrm{~K}$ under non-isothermic conditions plus increase in pressure up to $3 \mathrm{MPa}$ will change the overall conversion from 0.79 to $0.97[67]$.

In 2008, Wang et al. [68] modeled an FTS in a slurry bubble reactor. Then, they used the result from the analysis of different parameters to optimize the process. Their studying range for process conditions were $T=$ 523-573 K, $P=1-3 \mathrm{MPa}$, and $\mathrm{H}_{2} / \mathrm{CO}=1-3$. The result is as expected. Higher gas velocities will result in lower conversion of synthesis gas due to the lower retention time of the component. The increase in the temperature of the reaction will increase the selectivity of gasoline and diesel. Furthermore, above $550 \mathrm{~K}$ the selectivity of methane and $\mathrm{C}_{21}^{+}$will decrease. It means that the higher temperature is favorable for gasoline production with FTS. The effect of pressure is also considerable. The higher pressures will increase the selectivity of $\mathrm{C}_{21}^{+}$dramatically and also decrease the selectivity of gasoline. So as an optimum condition for gasoline production it is better to work in higher temperatures and lower pressures. The impact of $\mathrm{H}_{2} / \mathrm{CO}$ ratio is interesting, because it shows an optimum point for the highest selectivity of gasoline. Increasing the $\mathrm{H}_{2} / \mathrm{CO}$ ratio in the feed will decrease the selectivity of $\mathrm{C}_{21}^{+}$continuously and increase the selectivity of methane. The optimum ratio for highest gasoline production is 1.5. The optimum process condition and the Co conversion are shown in Table 3 [68].

In 2011, Khadzhiev et al. studied the FTS over Fe-based catalyst in a slurry reactor. Although the main goal of their article was to study the catalyst itself, but the data they gathered for the slurry reactor are useful. Under the conditions of $T=573 \mathrm{~K}, P=30.1 \mathrm{bar}$, and $\mathrm{H}_{2} / \mathrm{CO}$ ratio of 2, they found the CO conversion of $61 \%$ which is much lower than that was reported by Wang et al. [55, 64].

Fernandes [61] approved the liquid phase enters the reactor at very low velocities so that the products can be withdrawn continuously. The syngas passes through the reactor as bubbles and exchanges mass with the liquid phase. To produce large and small bubbles, the velocity of the gas is high enough in a commercial process. As discussed, the reactor operates either at a churn-turbulent flow regime or heterogeneous regime. Thousands of cooling tubes or cooling coils are installed on the slurry reactor, with a heat exchange area that can be as high as $20 \mathrm{~m}^{2}$ per $\mathrm{m}^{3}$ of reactor $(\Delta H=-170 \mathrm{~kJ} / \mathrm{mol}$ of $\mathrm{CO})$. With direct FTS it is not possible to produce paraffins of a specified carbon number range in high yields, but it may possible by directing the synthesis toward heavy paraffins, which are subsequently cracked selectively in a second reactor. Considering the simulations, to achieve maximum production yield of diesel, the optimized operating condition is at high pressures, a low catalyst holdup, and high gas superficial velocity. Higher $\mathrm{H}_{2} / \mathrm{CO}$ ratios satisfy higher production of low molecular weight products such as gasoline, on the other hand, lower $\mathrm{H}_{2} / \mathrm{CO}$ ratios favor the maximum production yield of heavy hydrocarbons [61].

Although slurry bubble column reactor are very good choice for LTFT synthesis, but for HTFT it is not the same. Besides this fact, this reactor presents also some drawbacks:

(1) Considering low catalyst concentration compared to fixed-bed, large reactors are required; 
(2) Reliable scale-up and design criteria are still missing: for instance a too high liquid recirculation could generate catalyst attrition and internals abrasion;

(3) The continuous separation of fine solid catalyst particles from the liquid products is difficult;

(4) Slurry handling requires careful design to avoid plugging

\subsection{Product intensifier reactor}

\subsubsection{Dual-type membrane reactor}

A dual-type reactor consists of a shell and tube heat exchanger reactor in which this reactor, water-cooled reactor, is combined in series with the second one, synthesis gas-cooled reactor. In the proposed configuration, hydrogen is withdrawn from the fresh feed synthesis gas and is injected to the ending segment of reactor in order to control dozing of hydrogen along the reactor and prevention of hydrogen waste. The cold feed synthesis gas is preheated inside the tubes of the fluidized-bed reactor, then it is fed into the tubes of the water-cooled reactor that is an isothermal reactor, and the chemical reactions are initiated by the catalyst. In this stage, synthesis gas is partly converted to hydrocarbons. The reacting gas leaving water-cooled reactor is directed into the shell side of the gas-cooled reactor in counter-current mode with synthesis gas flowing through the tubes and the reactions are completed in shell side. Due to highly exothermic chemical reactions, the fluidized-bed membrane dualtype reactor concept for FTS is considered, and the twophase theory of fluidization is used to model and simulate the proposed reactor. The wall of the tubes in the gascooled reactor is coated with the perm-selective $\mathrm{Pd}$ membrane which transmits hydrogen to the reaction side in consequence of the hydrogen partial pressure driving force. In many hydrogen-related reaction systems, Pdalloy membranes on a stainless steel support were used as the hydrogen-permeable membrane. Palladium-based membranes have been used for decades in hydrogen extraction because of their high permeability and good surface properties. Moreover, palladium is $100 \%$ selective for hydrogen transport. These membranes combine excellent hydrogen transport and discrimination properties with resistance to high temperatures, corrosion, and solvents. Key requirements for the successful development of palladium-based membranes are low costs as well as perm-selectivity combined with good mechanical, thermal, and long-term stability [69, 70].
The distributed feed of reactants through a membrane allows for better temperature control. Furthermore, the methane selectivity can be influenced, because it depends on the $\mathrm{H}_{2} / \mathrm{CO}$ ratio. Thus, a distribution of $\mathrm{H}_{2}$ in a stream of $\mathrm{CO}$ can lead to an increase in the yield of heavy products. The group of Schaub from the University of Karlsruhe in Germany investigated in situ water removal with membranes. Water produced during FTS may negatively influence the reaction by re-oxidation of catalysts, increasing water/gas shift activity, and decreasing partial pressures of the educts. The in situ removal of water requires highly selective membranes for effective removal of water without loss of educts and enhancement of $\mathrm{CO}_{2}$ conversion to long-chain hydrocarbons by equilibrium displacement through the selective removal of $\mathrm{H}_{2} \mathrm{O}$ [15].

The benefits of the fluidized-bed membrane reactor concept over fixed-bed membrane reactor concept are the absence of radial and axial temperature gradients due to the excellent heat transfer characteristics of fluidization, much better utilization of the catalyst particles (no internal diffusion limitations), because very small catalyst particles can be used while maintaining a very small pressure drop, very high flexibility for insertion of membranes in the reactor because of minimizing thermal stress in the membrane, the particle size in fluidizedbed reactors is not constrained by the pressure drop and can be chosen to achieve optimal catalyst utilization and isothermal operation. Membranes can improve fluidization behavior as a result of compartmentalization and reduced average bubble size due to enhanced bubble breakage resulting in improved bubble to emulsion mass transfer [71, 72].

A combination of fixed-bed and slurry bubble column membrane reactors for FTS was proposed by Rahimpour et al. in 2012 [31]. In the first catalyst bed which is fixed-bed reactor, a part of syngas is converted to hydrocarbons. In the second bed, the heat of reaction is used to preheat the feed synthesis gas to the first reactor. This reactor is a membrane-assisted slurry bubble column reactor, as it is shown in Figure 11. The change in the gasoline yield is small, from $660 \mathrm{~g} / \mathrm{g}$ feed to $710 \mathrm{~g} / \mathrm{g}$ feed.

Although the obtained results propose that utilization of this type of reactor may be feasible and beneficial, experimental tests are required to prove the validity and safe operation of the suggested reactor [31].

In 2009, Rahimpour et al. [71, 72] optimized a configuration which is a fixed- and fluidized-bed hydrogen perm-selective membrane reactor (FMDR) by mean of genetic algorithm. Configuration of this reactor is shown in Figure 12. The optimization results show that the best 


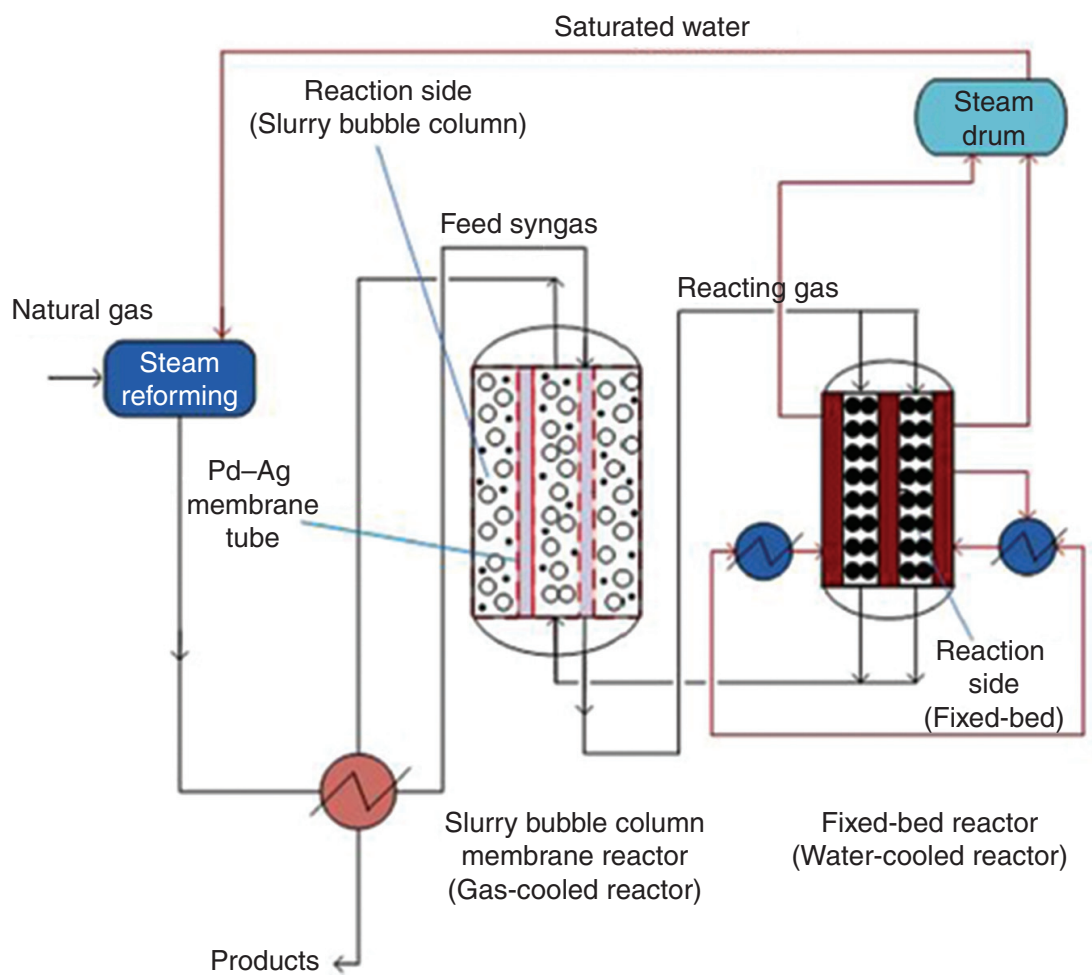

Figure 11 Slurry bubble column dual-type FTS membrane reactor (SDMR)

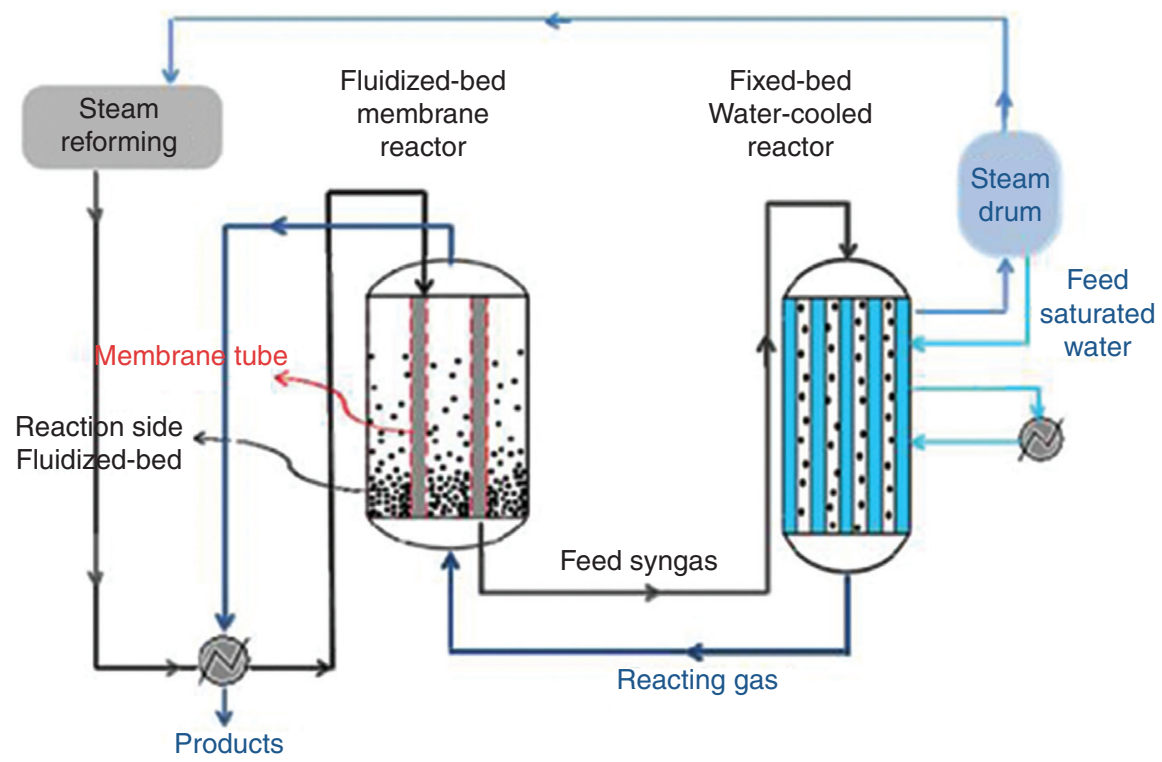

Figure 12 Fixed-bed cascading with fluidized-bed membrane reactor

condition should change a bit. The final parameters are shown in Table 4. In the optimized FMDR, the gasoline production yield is increased up to $1,000 \mathrm{~g} / \mathrm{g}$ feed. The CO conversion shows a slight increase to $81 \%$. More important, there is a significant decrease in production of carbon dioxide and methane which are about half of the amount before the optimization [71, 72].

In 2011, a new configuration has been proposed by Rahimpour et al. [56]. In this configuration a fixed-bed water perm-selective membrane reactor is followed by a 
Table 4 Summary of some theoretical reports on CO conversion values based product intensifier reactors for a few selected results

\begin{tabular}{|c|c|c|c|c|c|c|c|}
\hline Number & Reactor & Catalyst & Temp. (K) & Press. (bar) & $\mathrm{H} 2 / \mathrm{CO}$ in feed & CO conversion (\%) & Reference \\
\hline \multicolumn{8}{|c|}{ Dual-type membrane reactors } \\
\hline 1 & SDMR & Fe-HZSM5 & 573 & 17 & 0.96 & 79 & [76] \\
\hline 2 & FMD & Fe-HZSM5 & 573 & 23 & 1.02 & 81 & {$[71,72]$} \\
\hline 3 & FMFMDR & Fe-HZSM5 & 565 & 17 & 0.96 & 84 & [56] \\
\hline 4 & TCMDR & Fe-HZSM5 & 565 & 17 & 0.96 & 94 & [56] \\
\hline 5 & CFMR & Fe-HZSM5 & 569 & 17 & 0.96 & 92 & [78] \\
\hline 6 & FMFMDR & Fe-HZSM5 & 573 & 17 & 0.96 & 84 & [80] \\
\hline 7 & MDR & Fe-HZSM5 & 569 & 17 & 0.96 & 77 & [78] \\
\hline 8 & MR & Fe-HZSM5 & 569 & 35 & 0.96 & 80 & [75] \\
\hline \multicolumn{8}{|c|}{ Thermally coupled reactors } \\
\hline 1 & TCR & Fe-HZSM5 & 623 & 23 & 0.96 & 99.8 & [78] \\
\hline 2 & TCMR & Fe-HZSM5 & 614 & 23 & 1.4 & 97 & [81] \\
\hline 3 & DCTCMR & $\mathrm{Fe}-\mathrm{Cu}-\mathrm{K}-\mathrm{SiO}_{2}$ & 614 & 17 & 0.96 & 86 & [82] \\
\hline 4 & CTCMR & $\mathrm{Fe}-\mathrm{Cu}-\mathrm{K}-\mathrm{SiO}_{2}$ & 614 & 17 & 0.96 & 88 & [73] \\
\hline 5 & TCTCMR & Fe-HZSM5 & 565 & 17 & 0.96 & 81 & [79] \\
\hline 6 & CLLTCR & Fe-HZSM5 & 565 & 17 & 0.96 & 78 & [76] \\
\hline
\end{tabular}

fluidized-bed hydrogen perm-selective membrane reactor [(fixed-bed membrane and fluidized-bed membrane dual reactor (FMFMDR)] which is shown in Figure 13. The tube walls of the fixed-bed reactor of FMFMDR configuration are coated by a high water perm-selective membrane layer. To show the improvements in this design, the obtained result of the performance is compared with a fluidized-bed membrane dual-type reactor (FMDR) and a
CR for FTS. CO conversion in FMFMDR is $84 \%$ which is higher than 81\% for FMDR and 78\% for CRs. Results show that the gasoline yield in FMFMDR is higher than the one in FMDR. The FMFMDR configuration not only decreases the production of undesired product such as $\mathrm{CO}_{2}$ but also produces more gasoline [56].

Rahimpour et al. used the thermally coupled reactor concept and made a combination with dual reactors

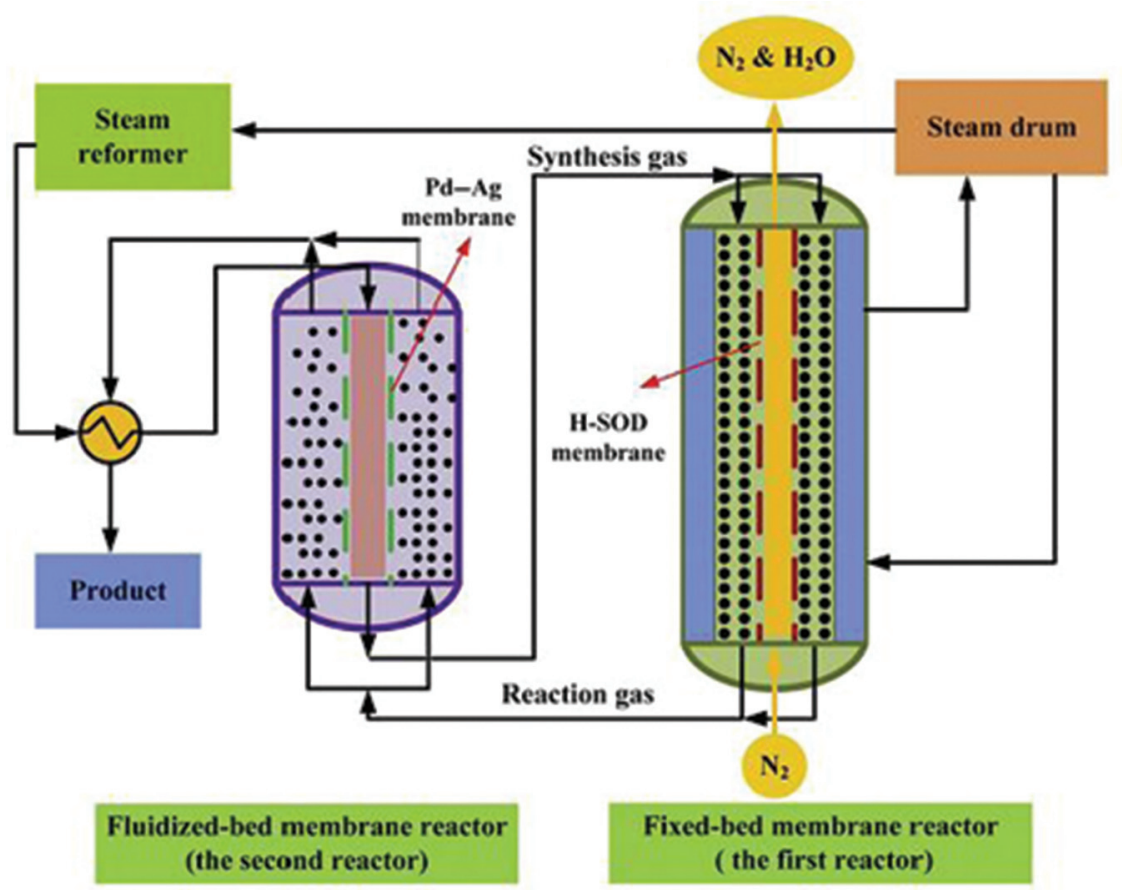

Figure 13 fixed-bed membrane and fluidized-bed membrane reactor (FMFMDR) 


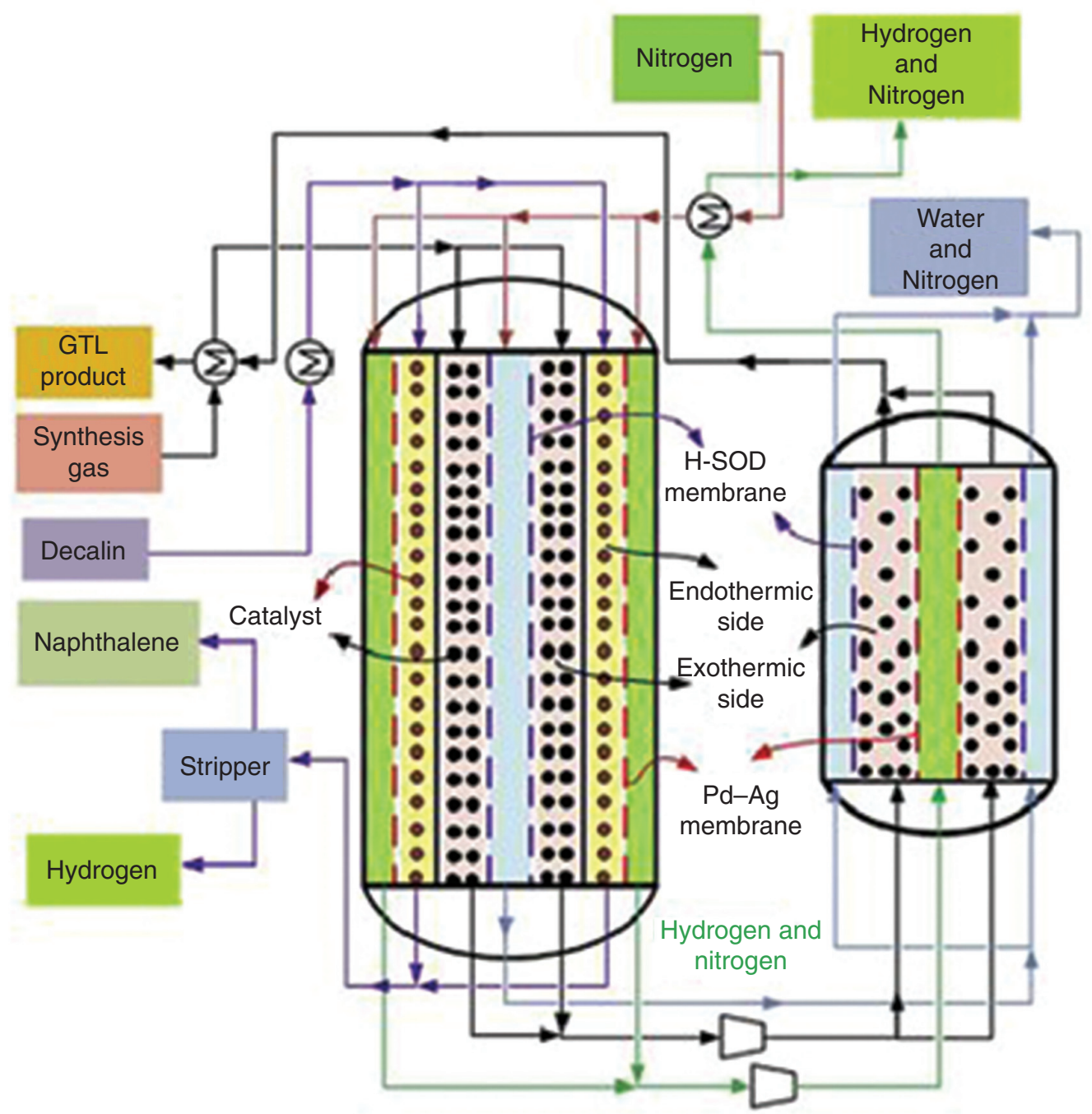

Figure 14 Thermally coupled membrane dual-type reactor (TCMDR)

concept in 2012. The scheme of this configuration is shown in Figure 14. For simultaneous hydrogen production and utilization in GTL technology, they proposed a thermally coupled membrane dual-type reactor (TCMDR). To improve the heat transfer between exothermic and endothermic sides, in this configuration dehydrogenation of decalin is coupled with FTS reaction. Pd-Ag and Hydroxy-Sodalite membrane layers are used to improve the mass transfer between exothermic/endothermic side and permeation side. The results show that the gasoline yield in TCMDR is about $17 \%$ higher than the yield in FMDR and 29\% higher in comparison with CR. The increase in gasoline and hydrogen yields illustrates the preference of TCMDR to the FMDR and CRs [73, 83].

A cascading fluidized-bed membrane reactor (CFMR) has been proposed in 2011 by Rahimpour et al. [56]. The different features and performances of this kind of reactor have been studied. Finally, they compared this new configuration with a fixed-bed membrane cascading with fluidized-bed membrane reactor (FMFMDR). As shown in Figure 15, the CFMR configuration consists of a fluidizedbed water perm-selective membrane reactor followed by a fluidized-bed hydrogen perm-selective membrane reactor. On the other side, a fixed-bed concept is used in the first reactor for the FMFMDR. The performance of CFMR is compared with FMFMDR in order to demonstrate the effect of fluidization concept on the reactor performance. The modeling results show an increase of $5.3 \%$ in the gasoline production yield and $12 \%$ decrease in $\mathrm{CO}_{2}$ production yield in CFMR in comparison with FMFMDR. This fact means that it is better to apply the fluidized-bed concept instead of a fixed-bed concept [56].

In 2010, Rahimpour et al. [74] made a comparison of co-current and counter-current modes of operation for a 


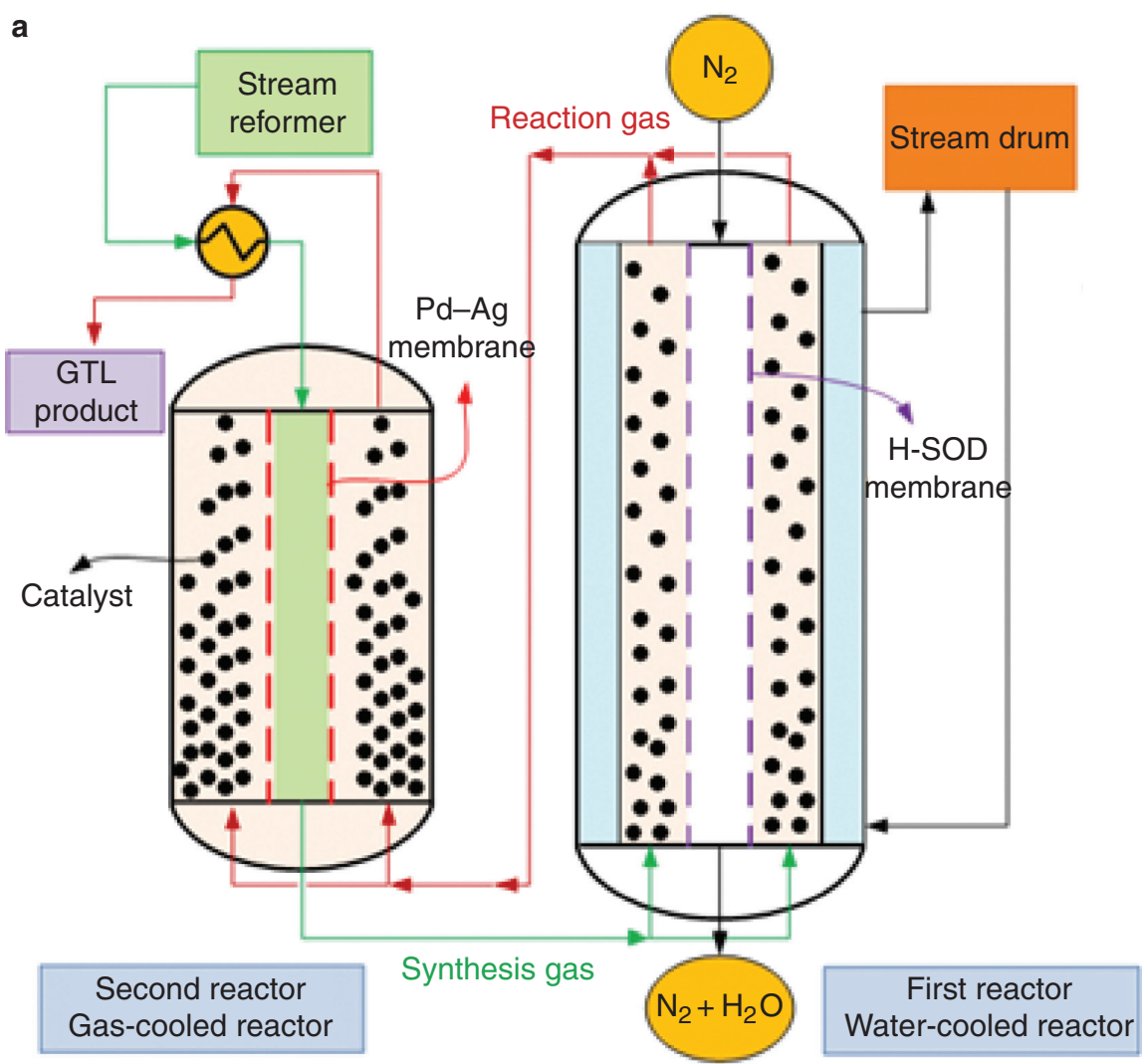

Figure 15 Cascading fluidized-bed membrane dual-type FTS reactor (CFMR)

novel hydrogen perm-selective membrane reactor. In both modes of operations, a system with two catalyst bed instead of one single catalyst bed is developed for FTS reactions. The first reactor is a conventional watercooled fixed-bed reactor and the second reactor is a membrane fixed-bed reactor. In the first catalytic reactor, the synthesis gas is partially converted to products, then in the second reactor the FTS reactions are completed and heat of reaction is used to preheat the entering syngas to the first reactor. In the co-current mode, feed gas enters the tubes of the second reactor in the same direction with the reacting gas flow in shell side, while in the counter-current mode the gas streams are in the opposite direction. The counter-current mode of operation decreases undesired products such as $\mathrm{CO}_{2}$ and $\mathrm{CH}_{4}$ and also produces more gasoline [74]. A summary of the different dual-type membrane reactors are shown in the first part of Table 4. The CO conversions and corresponding working conditions are categorized in this table.

In 2009, Forghani et al. [75] proposed a hydrogen perm-selective membrane reactor for FTS. This reactor is simulated, and finally it is compared with the CRs for HTFTS. The results of the simulation show $4.45 \%$ increase in gasoline production yield in comparison with $\mathrm{CR}$ and also $6.16 \%$ reduction in $\mathrm{CO}_{2}$ formation. Obtained results demonstrate that the proposed membrane FTS reactor system is an interesting candidate for increasing the gasoline production from synthesis gas. Summary of the working condition and performance of this reactor is shown in Table 4 [75].

Membrane reactors can be utilized separately for FTS without any combination with other reactors or coupling. In this configuration, the synthesis gas enters the tube side, and reacting gas mixture is fed to the shell side of the reactor. The flows are in co-current mode. The synthesis gas can be preheated by heat which is produced by the reaction. Due to the hydrogen partial pressure difference, hydrogen can penetrate from the feed synthesis gas side into the reaction side. The exiting synthesis gas from tube side is recycled to shells, and the chemical reaction takes place in catalytic bed. This way the reacting gas in shell side is cooled simultaneously with passing gas in tube and saturated water in outer shell [75]. A conventional scheme of membrane reactor is shown in Figure 16.

The general advantages of membrane reactors as compared to sequential reaction-separation systems are:

(1) Increased reaction rates.

(2) Reduced byproduct formation. 


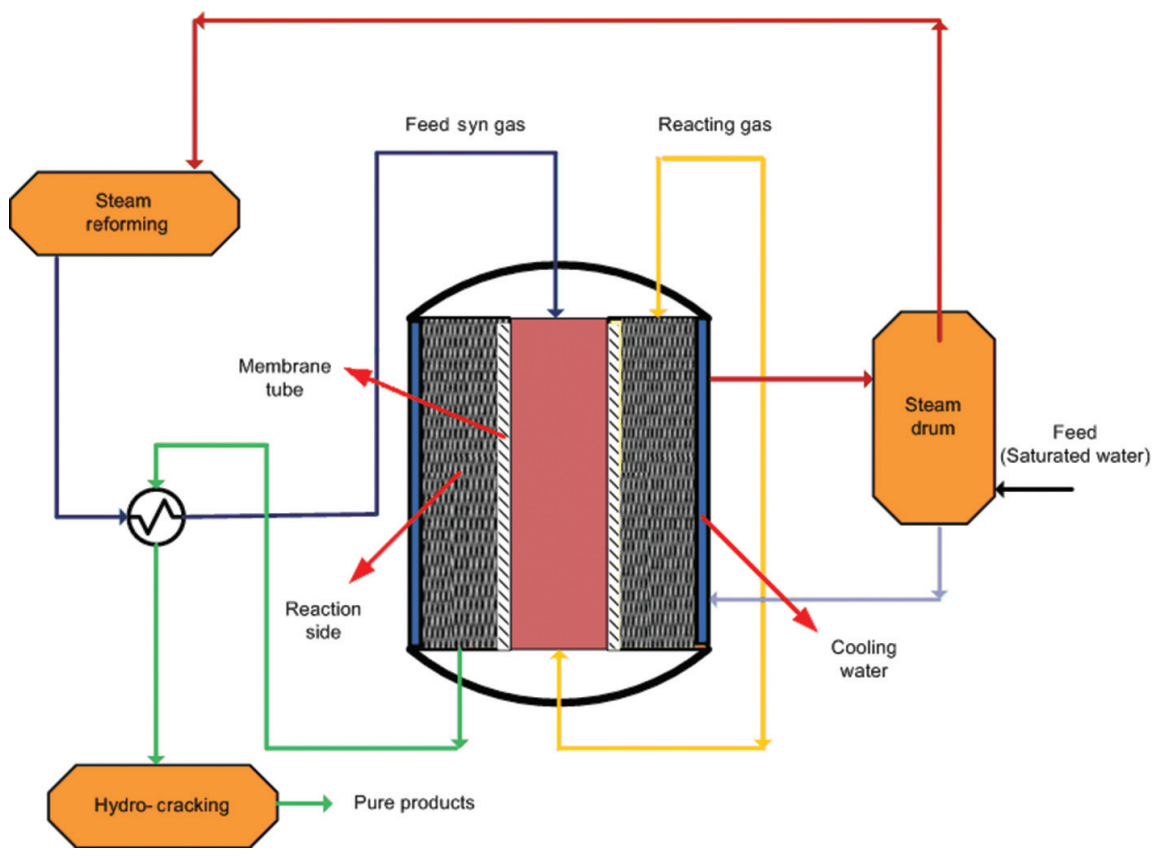

Figure 16 Membrane FT reactor

(3) Lower energy requirements.

(4) The possibility of heat integration.

(5) Distributed feed of reactants.

(6) In situ removal of water forced through membrane contactor.

(7) Zeolite encapsulated catalysts.

These advantages potentially lead to compact process equipment that can be operated with a high degree of flexibility [76].

A membrane reactor was suggested to convert the refineries natural purge gases into liquid hydrocarbons in 2011 by Rahimpour et al. [56]. This process is supposed to be an alternative to gas flaring. The ultimate objective of this work was to evaluate the possibility of using a typical GTL synthesis loop for recycling waste natural gas in refineries for minimizing $\mathrm{CO}_{2}$ emissions and producing liquid fuel such as gasoline. To achieve this goal, purged natural gas is converted to syngas in a novel hydrogen perm-selective membrane reactor with recycle stream, and then it is converted to liquid fuel in FT membrane reactor. In this design, a loop is constructed by returning and mixing a part of the product with the original feed through recycle stream. The simulation results of the aforesaid loop show decrease in $\mathrm{CO}_{2}$ emission rate with a value of $1 / 10$ to that of flaring, with production of 0.018 $\mathrm{kg} \mathrm{mol} / \mathrm{s}$ of hydrogen and more than 90 barrels per day of heavy fraction hydrocarbons containing gasoline and butane fraction for a specified value of (about 4 MMscfd) purge gases [56].

\subsubsection{Coupling configurations reactor}

Thermally coupled reactor, in fact, works like a shell and tube heat exchanger in which an exothermic reaction operates as a heat source of an endothermic reaction that modified using a hydrogen perm-selective membrane as the shell of the reactor to separate the produced hydrogen from the dehydrogenation process [77]. Permeated hydrogen enters another section called permeation side to be collected by Argon, known as the sweep gas. With the help of this novel configuration, there is no need to consume some amount of energy for cooling operation, and in addition there is a better control on the thermal energy generated from the exothermic reaction. Some other advantages of coupled reactors in comparison with CR are as follows: both exothermic and endothermic reactions are carried out simultaneously in a single vessel, and the equipment size will be reduced. Furthermore, the heat loss in this condition will be less than CRs, and at last the capital and operational costs will reduce [31]. In 2010, Rahmipour et al. [78] optimized a thermally coupled reactor with differential evolution method. This coupled reactor contains dehydrogenation of cyclohexane besides FTS. The objective of the 


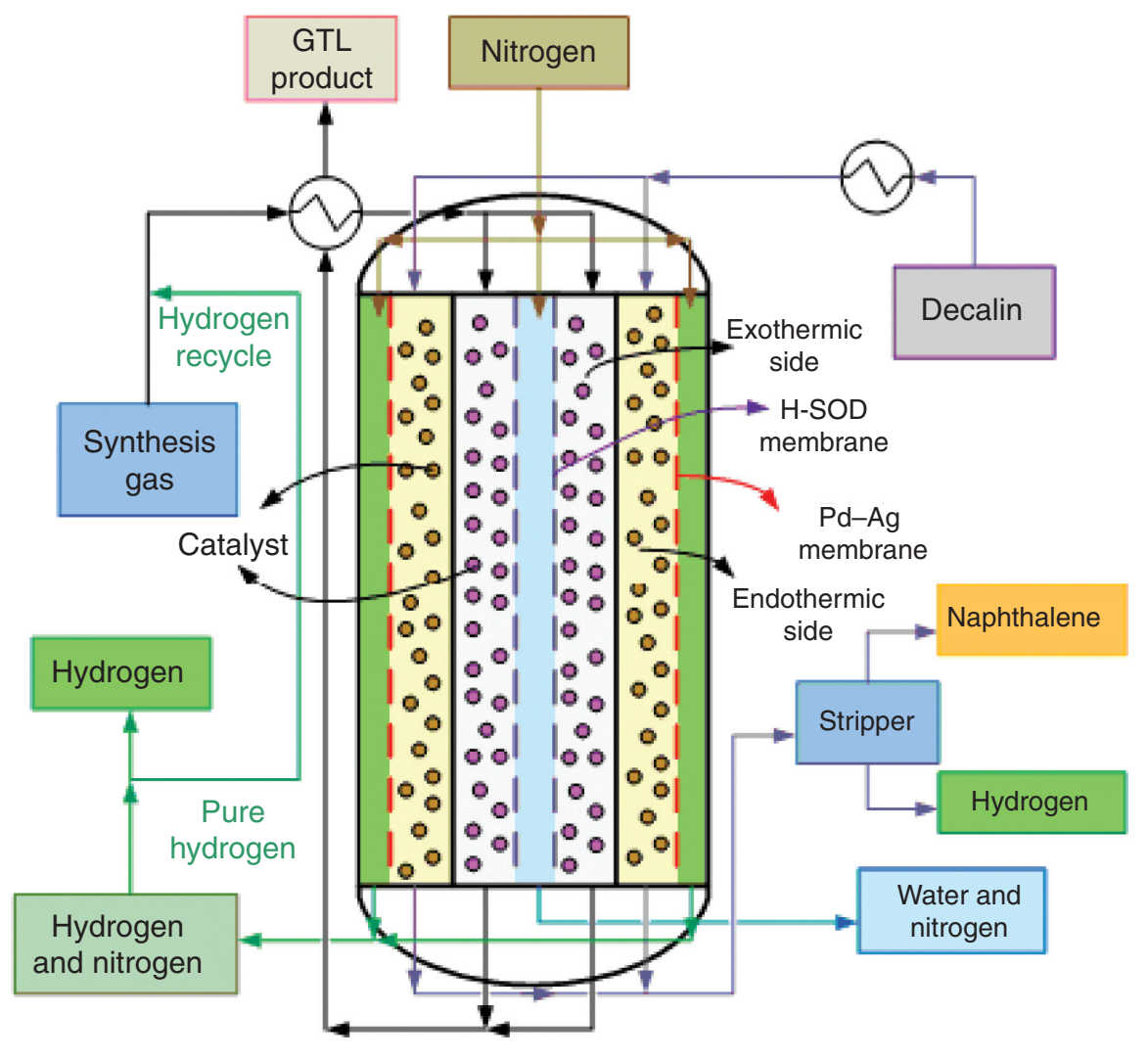

Figure 17 TCMR

optimization is to optimize the gasoline production yield. The proposed reactor is a heat exchanger reactor consists of two fixed bed of catalysts separated by the tube wall with the ability to transfer the produced heat from the exothermic side to the endothermic side. The working temperature range of benzene synthesis is between 423 $\mathrm{K}$ and $523 \mathrm{~K}$ which takes place on $\mathrm{Pt} / \mathrm{Al}_{2} \mathrm{O}_{3}$ catalyst. Considering the result of the optimization, the best inlet temperature of the reactant for exothermic side decided to be $623 \mathrm{~K}$ which is a bit higher than the limiting temperature suggested by Marvast et al. to avoid catalyst deactivation. The optimized temperature for the endothermic side is $498 \mathrm{~K}$. The results show that the CO conversion is $100 \%$ which is $22 \%$ higher than the CR. The objective of the study is satisfied by increasing the gasoline production yield to $14 \mathrm{~g} / \mathrm{g}\left(\mathrm{H}_{2}+\mathrm{CO}\right)$ in the reactor outlet which means 100\% increase in the yield [74].

An optimization of a thermally coupled membrane reactor (TCMR) has been done in 2009 by Rahimpour et al. [71, 72] in order to increase the hydrogen production in the endothermic side and the gasoline production yield in the exothermic side. The authors used differential evolution method to achieve their goal. The selected reaction for the endothermic side is dehydrogenation of decalin. The reactor scheme is shown in Figure 17. As the result of optimization, the different parameters have been decided. Inlet temperature of FTS feed is $614.28 \mathrm{~K}$, The inlet pressure is 23 bar, and the $\mathrm{H}_{2} / \mathrm{CO}$ ratio in the feed is 1.4. The optimized reactor has $14.8 \%$ more production yield of gasoline in comparison with CRs. The CO conversion is also increased up to $97 \%$ [56].

In 2011, the impact of different reactions in the endothermic side, on the performance of the thermally coupled reactors, has been studied by Rahimpour et al. [56]. The reactors are decalin TCMR (DCTCMR) which contains dehydrogenation of decalin in the endothermic side and cyclohexane TCMR (CTCMR) in which the dehydrogenation of cyclohexane takes place in the endothermic side. The results show that the CO conversion is $86 \%$ for DCTCMR which is a bit lower than $88 \%$ of CTCMR. Both reactors show much higher $\mathrm{CO}$ conversion in respect to $77 \%$ for CRs. The gasoline production yield is also increased from $700 \mathrm{~g} / \mathrm{g}$ feed for CR to $910 \mathrm{~g} / \mathrm{g}$ feed for DCTCMR and $940 \mathrm{~g} / \mathrm{g}$ feed for CTCMR. Although CTCMR shows higher CO conversion and gasoline production yield but a comparison between the modeling results of two reactors indicates that DCTCMR is better considering the higher hydrogen production compared with CTCMR 
which is 17 times higher. Moreover, higher $\mathrm{H}_{2}$ recovery yield which is about 12 times higher and faster dehydrogenation reaction rate in DCTCMR than CTCMR demonstrates that decalin is one of the best hydrogen carriers [56].

A novel thermally coupled multi-tubular two-membrane has been proposed by Bayat and Rahimpour in 2012 to increase the gasoline production yield. Decomposition of ammonia takes place in the endothermic side. This reactor has two different membranes, one is for permeation of pure hydrogen from exothermic into endothermic side and the other one is for separation of water from exothermic side. The scheme of this reactor is shown in Figure 18. Although the inlet temperature of the exothermic side is $565 \mathrm{~K}$ which is a bit lower than $673 \mathrm{~K}$, the minimum temperature for HTFTS range, we can assume this condition as high-temperature synthesis because the temperature will reach $573 \mathrm{~K}$ inside the reactor. The obtained results show that with this new configuration gasoline production yield is increased $27.14 \%$ in comparison with conventional fixed-bed reactor. Furthermore, there is $35.2 \%$ decrease in $\mathrm{CO}_{2}$ production

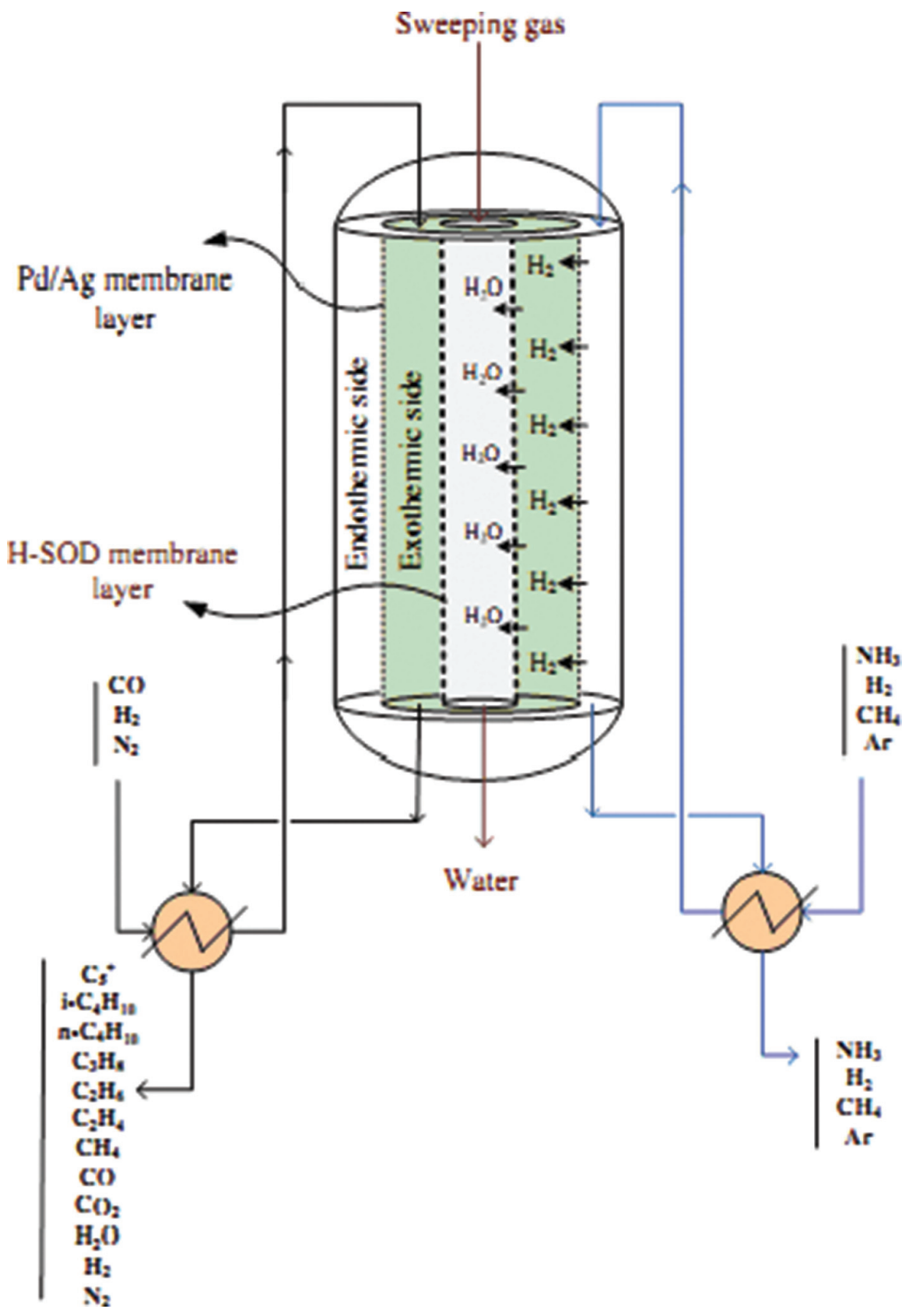

Figure 18 Thermally coupled multi-tubular two-membrane reactor (TCTCMR) 


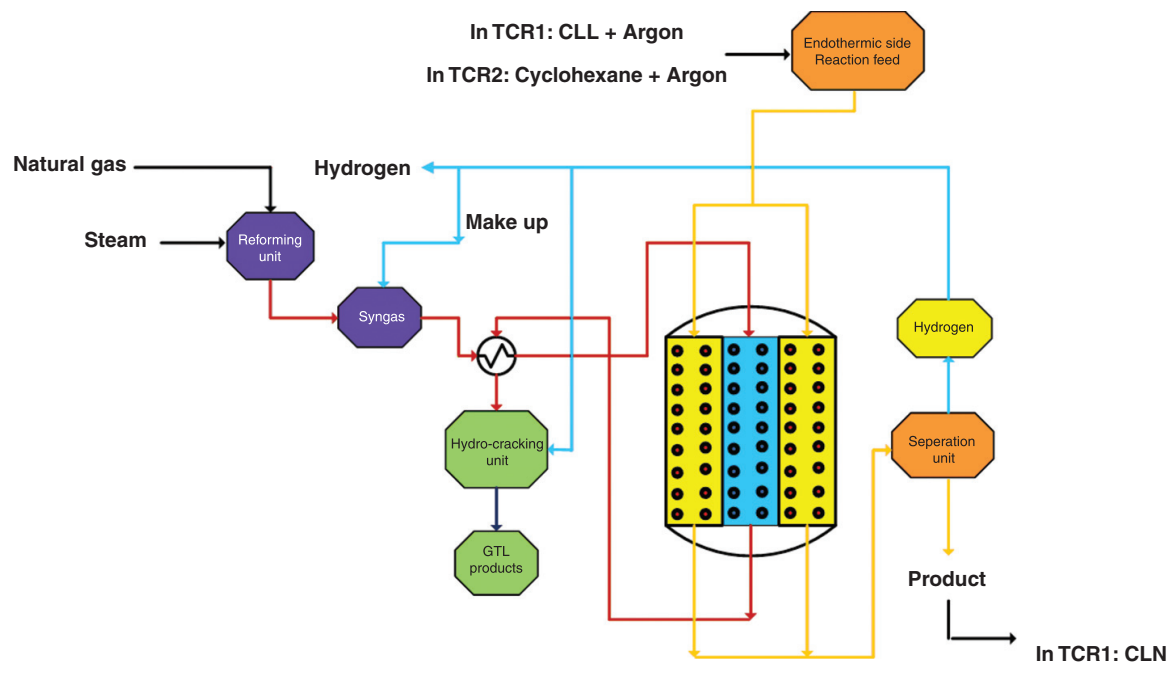

Figure 19 Thermally coupled reactor configuration and different feeds

yield which is a very important enhancement for this synthesis [79].

In 2012, Rahimpour et al. [31] made a comparison between two different thermally coupled reactors. One contains the dehydrogenation of cyclohexanol (CLL) in the endothermic side (TCR1), and the other one contains dehydrogenation of cyclohexane (CLN) in that side (TCR2). The reactor scheme with two different feeds for the endothermic side is shown in Figure 19. The results show that the CO conversion in TCR1 is almost the same as CR which is about $78 \%$ while the CO conversion in TCR2 is $81 \%$. On the other hand, the gasoline production yield for TCR1 is 1,100 $\mathrm{g} / \mathrm{g}$ feed in its optimized working condition, the value which is much higher than $900 \mathrm{~g} / \mathrm{g}$ feed of gasoline production yield for TCR2. Selectivity of $\mathrm{CO}_{2}$ is decreased dramatically in TCR1. This reduction is from $339 \%$ in CR to $173 \%$ in TCR1. As we can find the configuration with dehydrogenation of cyclohexanol in endothermic side shows better performances in gasoline production yield and reduction of undesired products [31].

Table 4 is a summary of the reactors studied in the section of product intensifier reactors. Although some of the simulations need further studies and experimental tests to demonstrate the practicality of the reactors but as it is discussed before, the new novel configurations for HTFTS show higher CO conversions.

\section{Discussion and conclusion}

As mentioned before, the main goal of HTFTS reaction is to produce lighter cuts such as diesel and gasoline. Thus features of different types of reactor investigated considering mainly CO conversion and gasoline production yield. The other important aspects were the ease of operation, safety, and economic issues. The main points for each reactor are summarized to decide the best choice for HTFTS.

The first reactor reviewed in this paper was fixed-bed reactors. This reactor was the first reactor for FTS. Fixedbed reactors will be commercialized very soon even if they have some problems. The main problem for this reactor is the cooling system to remove the heat produced by the synthesis. There were some improvements to satisfy the heat removing system needed. Multi-tubular reactor was a result of this modification. Even with the modifications and optimizations of multi-tubular reactors, the CO conversions in working plants are very low. The value for the conversion reported to be $78 \%$. Although multi-tubular reactors are more efficient than earlier ones in cooling system, there are still safety problems in controlling the temperature of the reactor especially in the case of temperature runaway. Figure 20 shows the temperature increase in a fixed-bed reactor which is about $23^{\circ} \mathrm{C}$.

As shown in Table 3, the slurry reactor is used normally for LTFT process which results in the production of high boiling temperature products such as wax and for this reason if we want to use this reactor for HTFT process in order to produce $\mathrm{C}_{5}^{+}$products such as gasoline we have to increase the temperature for example from 543 to $573^{\circ} \mathrm{C}$ and the pressure from 10 to $30.1 \mathrm{bar}$, while the feed ratio increases from 1.6 to 2 in comparison with fluidized-bed reactor which is naturally used for HTFT process. Moreover, the fixed-bed reactor functions in a wide range of temperature, pressure, and feed ratio and as it 


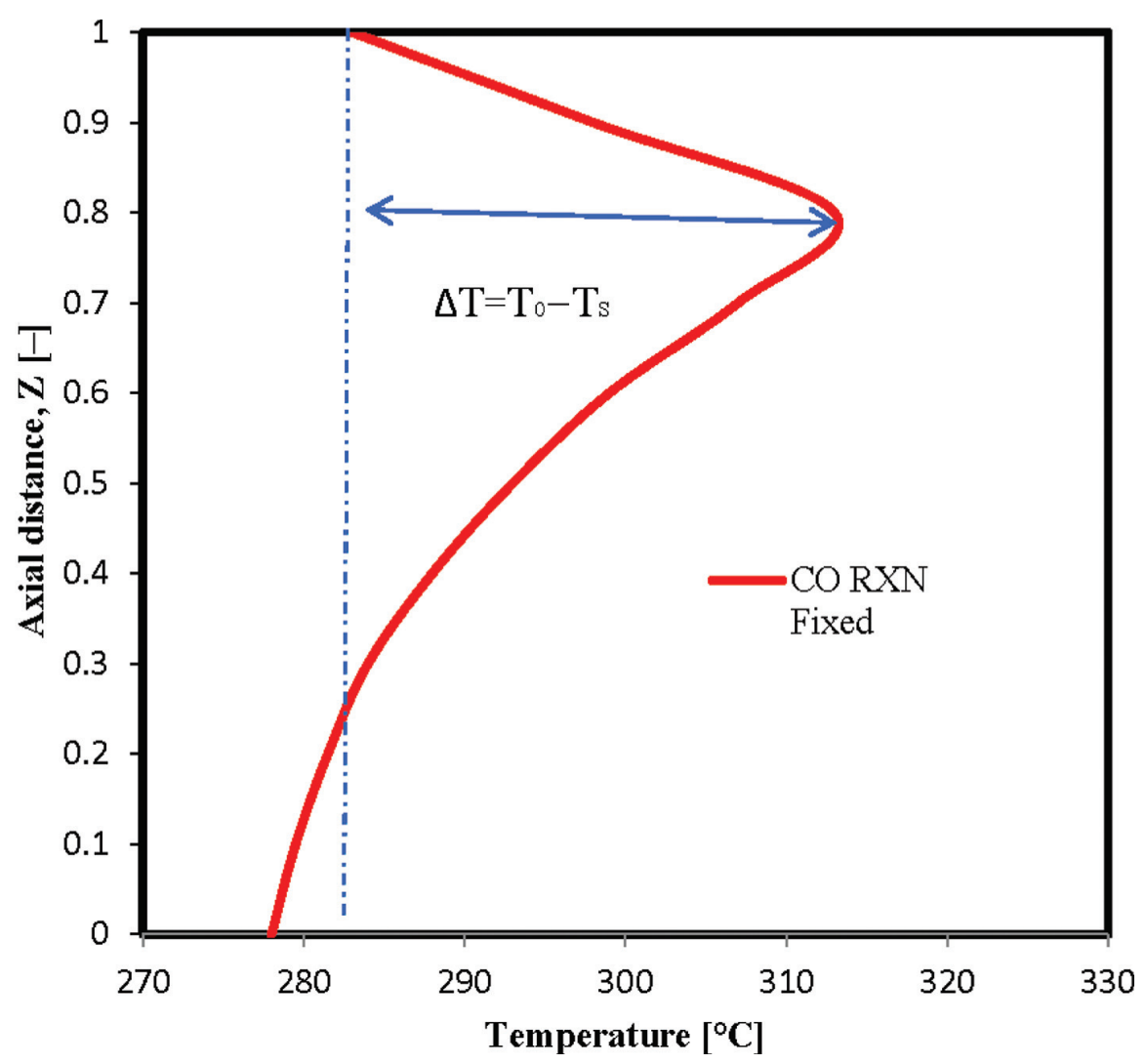

Figure 20 Axial temperature distribution of CO hydrogenation in the fixed-bed reactor [46]

can be seen from Table 3 the temperature differs from 573 to $674^{\circ} \mathrm{C}$ while the pressure increases from 18 to 47.5 bar with the feed ratio increase from 0.96 to 2 ; therefore, it is concluded that fluidized-bed reactor is the most appropriate reactor for HTFT process, since fixed-bed ranks second and slurry reactor ranks the last one.

Dual-type reactor is formed from a series of two reactors either fixed-bed reactor and fluidized-bed reactor or fixed-bed reactor and slurry reactor. As it can be seen from Table 4 for SDMR and FMFMDR with the same pressure and the same feed ratio, SDMR has got higher temperature but it still produces lower percentage of $\mathrm{CO}$ conversion; therefore, it can be concluded that dual-type reactor which includes fixed-bed and fluidized-bed reactor produces higher percentage of $\mathrm{CO}$ conversion for lower temperature, lower pressure, and lower feed ratio in comparison with the dual-type reactor which includes slurry reactor and fixed-bed reactor and that is why according to Table 4 Rahimpour and his colleagues have totally focused on the dual-type reactor which includes the fixed-bed and fluidized-bed reactors. Moreover, thermally coupled reactors have the ability to perform both endothermic and exothermic reactions in two sides of a reactor, connected with membrane; as it can be seen from Table 4, thermally coupled reactor (TCR) has got the highest level of CO conversion among the other TCRs with the $99.8 \%$ of CO conversion; therefore, TCR has been presented as the best type of reactor for HTFT process.

Recent studies and innovative reactor configurations for HTFTS eclipse our knowledge about the available reactors for HTFT. Higher performances and ease of operation provided by the product intensifier reactors persuade us to update the previous knowledge which was available about the utilizable reactors for HTFT. The diagram shown in Figure 5 at the beginning of the article is a famous diagram of available reactors for FTS which lacks the presence of product intensifier reactors. As the result of this article, this diagram is improved by considering recent studies. In Figure 21, the updated diagram is shown which contains the best reactor choice for HTFT product intensifiers. According to this figure HTFT product intensifier reactors cover a wide range while over lapping from slurry reactor zone to fluidized-bed reactor zone. Moreover, as it is seen when our HTFT product intensifier reactors include slurry and fixed-bed reactors, we need to increase the temperature and pressure strongly to get higher levels of gasoline production while HTFT product intensifier reactors 


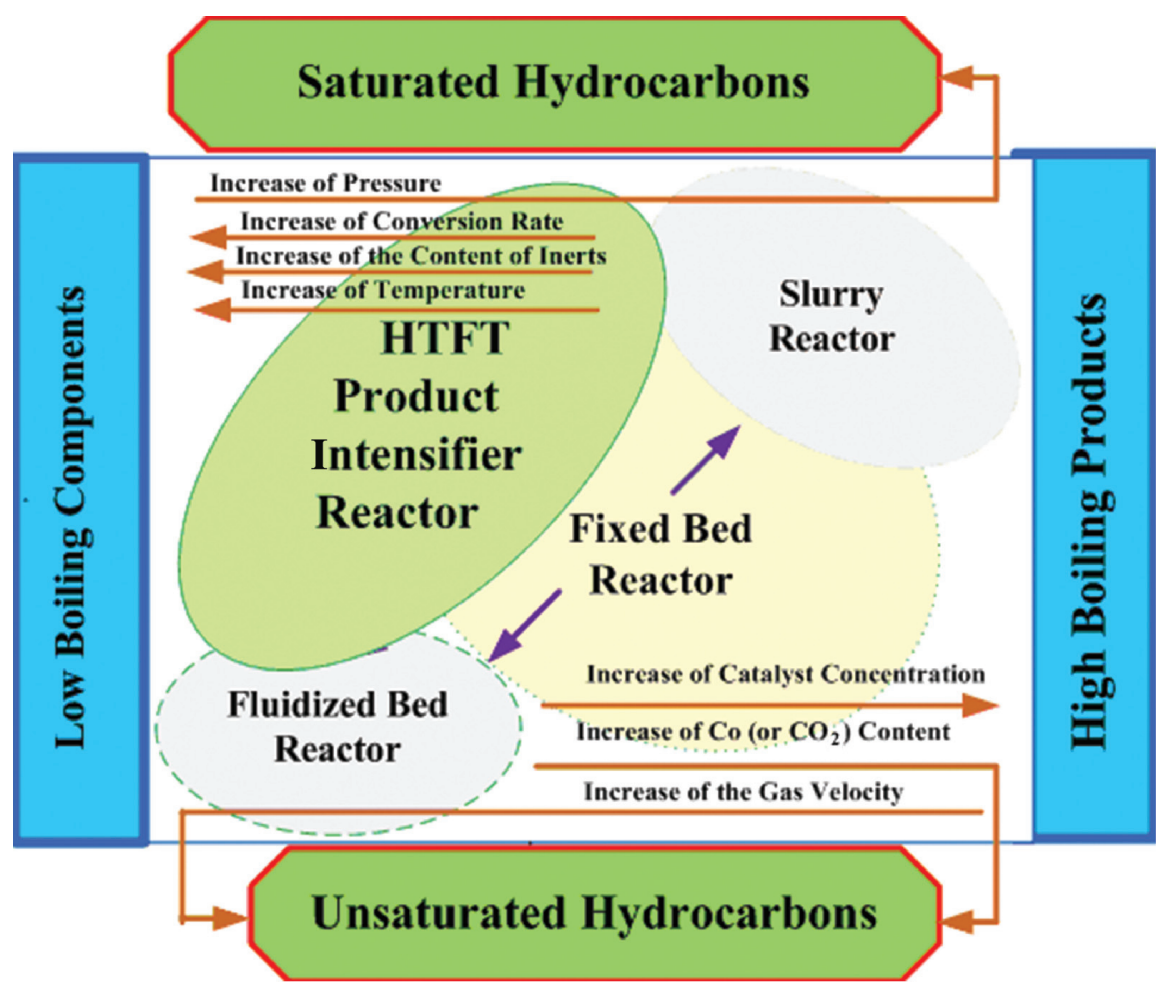

Figure 21 Influence of the process parameters in the different types of reactors on the product distribution including product intensifier reactors

consisting of fixed-bed and fluidized-bed reactors produce higher amount of gasoline in lower temperature and lower pressure condition and TCR location as the best HTFT product intensifier reactor is shown in Figure 21. Therefore, it can be said that this figure summarizes the results of Tables 3 and 4 .

\section{Abbreviations}

$\begin{array}{ll}\text { FTS } & \text { Fischer-Tropsch synthesis } \\ \text { GTL } & \text { Gas-to-liquids } \\ \text { ASF } & \text { Anderson-Schulz-Flory } \\ \text { LTFT } & \text { Low-temperature Fischer-Tropsch } \\ \text { HTFT } & \text { High-temperature Fischer-Tropsch } \\ \mathrm{X}_{\text {CO }} & \text { Carbon monoxide conversion } \\ \text { GHSV } & \text { Gas hour space velocity } \\ \text { CFB } & \text { Circulating fluidized bed } \\ \text { FFB } & \text { Fixed fluidized bed } \\ \text { FMDR } & \text { Fluidized-bed hydrogen perm-selective membrane } \\ & \text { reactor } \\ \text { FMD } & \text { Fixed-bed cascading fluidized-bed membrane dual } \\ & \text { reactor } \\ \text { FMFMDR } & \begin{array}{l}\text { Fixed-bed membrane and fluidized-bed membrane dual } \\ \text { reactor }\end{array} \\ \text { TCMDR } & \text { Thermally coupled membrane dual-type reactor } \\ \text { CR } & \text { Conventional reactor }\end{array}$

$\begin{array}{ll}\text { CFMR } & \text { Cascading fluidized-bed membrane reactor } \\ \text { TCMR } & \text { Thermally coupled membrane reactor } \\ \text { DCTCMR } & \begin{array}{l}\text { Declaim thermally coupled membrane reactor } \\ \text { CTCMR }\end{array} \\ \text { Cyclohexane thermally coupled membrane reactor } \\ \text { TCTCMR } & \text { Thermally coupled multi-tubular two-membrane reactor } \\ \text { SDMR } & \begin{array}{l}\text { Slurry bubble column dual-type FTS membrane } \\ \text { reactor }\end{array} \\ \text { MDR } & \text { Hydrogen perm-selective membrane reactor } \\ \text { MR } & \text { Membrane reactor } \\ \text { TCR } & \text { Thermally coupled reactor } \\ \text { CLLTCR } & \text { Cyclohexanol thermally coupled reactor }\end{array}$

\section{References}

1. Wang T, Wang J, Jin Y. Slurry reactors for gas-to-liquid processes: a review. Ind Eng Chem Res 2007; 46:5824.

2. Wei W, Du W, Xu J, Bao X. Study on a coupling reactor for catalytic partial oxidation of natural gas to syngas. Int J Chem Reactor Eng 2011;9:1-19.

3. Bartholomew $\mathrm{CH}$. Chapter 5 recent developments in Fischer-Tropsch catalysis. In: Guczi L, editor. Studies in surface science and catalysis. Elsevier, 1991:158-224. Netherlands.

4. Dry ME. The Fischer-Tropsch process: 1950-2000. Catalysis Today 2002;71:227.

5. Ansorge J, Bilton S, Van Der Ploeg HJ, Routier AM, Smit CJ. Coal to liquid processes. Google patents, 2005. 
6. Wood DA, Nwaoha C, Towler BF. Gas-to-liquids (GTL): a review of an industry offering several routes for monetizing natural gas. J Nat Gas Sci Eng 2012;9:196.

7. Bezergianni S, Dimitriadis A. Comparison between different types of renewable diesel. Renewable Sustainable Energy Rev 2013;21:110.

8. Czernik S, French R, Feik C, Chornet E. Hydrogen by catalytic steam reforming of liquid byproducts from biomass thermoconversion processes. Ind Eng Chem Res 2002;41:4209.

9. Dębowski M, Zieliński M, Grala A, Dudek M. Algae biomass as an alternative substrate in biogas production technologies review. Renewable Sustainable Energy Rev 2013;27:596.

10. Gupta KK, Rehman A, Sarviya RM. Bio-fuels for the gas turbine: a review. Renewable Sustainable Energy Rev 2010;14:2946.

11. Kolb G. Review: microstructured reactors for distributed and renewable production of fuels and electrical energy. Chem Eng Process Process Intensification 2013;65:1.

12. Swain PK, Das LM, Naik SN. Biomass to liquid: a prospective challenge to research and development in 21st century. Renewable Sustainable Energy Rev 2011;15:4917.

13. Tymchyshyn M, Yuan Z, Xu CC. Reforming of glycerol into bio-crude: a parametric study. Int J Chem Reactor Eng 2013;11:1.

14. Aasberg-Petersen K, Christensen TS, Dybkjaer I, Sehested J, Østberg M, Coertzen RM, et al. Chapter 4 - synthesis gas production for FT synthesis. In: André S, Mark D, editors. Studies in surface science and catalysis. Elsevier, 2004:258-405. Netherlands.

15. Guettel R, Kunz U, Turek T. Reactors for Fischer-Tropsch synthesis. Chem Eng Technol 2008;31:746.

16. Dry ME. The Fischer-Tropsch (FT) synthesis processes. In: Handbook of heterogeneous catalysis. Wiley-VCH Verlag GmbH \& Co, 2008, Ertl, Knözinger, Schüth, Weitkamp, Germany.

17. Velasco JA, Lopez L, Velásquez M, Boutonnet M, Cabrera S, Järås S. Gas to liquids: a technology for natural gas industrialization in Bolivia. J Nat Gas Sci Eng 2010;2:222.

18. de Deugd R, Kapteijn F, Moulijn J. Trends in Fischer-Tropsch reactor technology - opportunities for structured reactors. Top Catalysis 2003;26:29.

19. Remans TJ, Jenzer G, Hoek A. Gas-to-liquids, handbook of heterogeneous catalysis. Wiley-VCH Verlag GmbH \& Co. KGaA, 2008. Germany.

20. Liu G, Yan B, Chen G. Technical review on jet fuel production. Renewable Sustainable Energy Rev 2013;25:59.

21. Lozano-Blanco G, Thybaut JW, Surla K, Galtier P, Marin GB. Simulation of a slurry-bubble column reactor for FischerTropsch synthesis using single-event microkinetics. AIChE J 2009;55:2159.

22. Saeidi S, Amin NA, Rahimpour MR. Hydrogenation of $\mathrm{CO}_{2}$ to value-added products - a review and potential future developments. J CO2 Util 2014;5:66.

23. Guillou L, Paul S, Le Courtois V. Investigation of H2 staging effects on co conversion and product distribution for Fischer-Tropsch synthesis in a structured microchannel reactor. Chem Eng J 2008;136:66.

24. Rafiee A, Hillestad M. Staging of the Fischer-Tropsch reactor with an iron based catalyst. Comput Chem Eng 2012;39:75.

25. Florent Allain J-F, Falk L. Analysis of equilibrium shifting by inter-stage reactant feeding in a series of isothermal reactors. Int J Chem Reactor Eng 2014;12:1-17.
26. Knochen J, Güttel R, Knobloch C, Turek T. Fischer-Tropsch synthesis in milli-structured fixed-bed reactors: experimental study and scale-up considerations. Chem Eng Process Process Intensification 2010;49:958.

27. Dancuart LP, Steynberg AP. Fischer-tropsch based GTL technology: a new process? In: Davis BH, Occelli ML, editors. Studies in surface science and catalysis. Elsevier, 2007:379-99. Netherlands.

28. Singh A, Nizami A-S, Korres NE, Murphy JD. The effect of reactor design on the sustainability of grass biomethane. Renewable Sustainable Energy Rev 2011;15:1567.

29. Dehghani O, Gholipour MR, Shokrollahi Yancheshmeh MS, Seifzadeh Haghighi S, Ghaemi M, Rahimpour MR, et al. A new configuration for decoking process in series reactors. Chem Eng J 2013;215-216:418.

30. Mirvakili A, Rostami M, Paymooni K, Rahimpour MR, Moghtaderi B. Hydrogen looping approach in optimized methanol thermally coupled membrane reactor. Int J Hydrogen Energy 2012;37:235.

31. Rahimpour MR, Arabpour M, Iranshahi D, Raeissi S. Utilization of cyclohexanol dehydrogenation in a novel thermally coupled reactor for Fischer-Tropsch synthesis in gas to liquid technology. J Nat Gas Sci Eng 2012;9:138.

32. Rahimpour MR, Bahmanpour AM. Optimization of hydrogen production via coupling of the Fischer-Tropsch synthesis reaction and dehydrogenation of cyclohexane in GTL technology. Appl Energy 2011;88:2027.

33. Rahimpour MR, Mirvakili A. A novel configuration of decalin and hydrogen loop in optimized thermally coupled reactors in GTL technology via differential evolution method. J Ind Eng Chem 2013;19:508.

34. Hagey L, de Lasa HI. Conversion of synthesis gas into light hydrocarbons. Modelling of the catalytic reaction network, 2004.

35. Sie ST, Krishna R. Fundamentals and selection of advanced Fischer-Tropsch reactors. Appl Catalysis A Gen 1999;186:55.

36. Reddy Keshav T, Basu S. Gas-to-liquid technologies: India's perspective. Fuel Process Technol 2007;88:493.

37. Steynberg AP, Espinoza RL, Jager B, Vosloo AC. High temperature Fischer-Tropsch synthesis in commercial practice. Appl Catalysis A Gen 1999;186:41.

38. Jess A, Kern C. Modeling of multi-tubular reactors for FischerTropsch synthesis. Chem Eng Technol 2009;32:1164.

39. Lee TS, Chung JN. Mathematical modeling and numerical simulation of a Fischer-Tropsch packed bed reactor and its thermal management for liquid hydrocarbon fuel production using biomass syngas. Energy Fuels 2012;26:1363.

40. de Deugd RM, Chougule RB, Kreutzer MT, Meeuse FM, Grievink J, Kapteijn $\mathrm{F}$, et al. Is a monolithic loop reactor a viable option for Fischer-Tropsch synthesis? Chem Eng Sci 2003;58:583.

41. Elbashir N, Bao B, El-Halwagi M. An approach to the design of advanced Fischer-Tropsch reactor for operation in near-critical and supercritical phase media. In: Advances in gas processing: proceedings of the 1st annual symposium on gas processing symposium, 2009:423-33.

42. Ghasemi S, Sohrabi M, Rahmani M. A comparison between two kinds of hydrodynamic models in bubble column slurry reactor during Fischer-Tropsch synthesis: single-bubble class and twobubble class. Chem Eng Res Des 2009;87:1582.

43. Dry ME. Practical and theoretical aspects of the catalytic Fischer-Tropsch process. Appl Catalysis A Gen 1996;138:319. 
44. Davis B. Fischer-Tropsch synthesis: overview of reactor development and future potentialities. Top Catalysis 2005;32:143.

45. Tijmensen MJ, Faaij AP, Hamelinck $\mathrm{CN}$, van Hardeveld MR. Exploration of the possibilities for production of FischerTropsch liquids and power via biomass gasification. Biomass Bioenergy 2002;23:129.

46. Kim J-S, Lee S, Lee S-B, Choi M-J, Lee K-W. Performance of catalytic reactors for the hydrogenation of $\mathrm{CO}_{2}$ to hydrocarbons. Catalysis Today 2006;115:228.

47. Kolios G, Frauhammer J, Eigenberger G. Autothermal fixed-bed reactor concepts. Chem Eng Sci 2000;55:5945.

48. Schulz H. Short history and present trends of Fischer-Tropsch synthesis. Appl Catalysis 1999;3:3-12.

49. Rafiq MH, Jakobsen HA, Schmid R, Hustad JE. Experimental studies and modeling of a fixed bed reactor for FischerTropsch synthesis using biosyngas. Fuel Process Technol 2011;92:893.

50. Everson RC, Mulder H, Keyser MJ. The Fischer-Tropsch reaction with supported ruthenium catalysts: modelling and evaluation of the reaction rate equation for a fixed bed reactor. Appl Catalysis A Gen 1996;142:223.

51. Mazzone LC, Fernandes FA. Modeling of Fischer-Tropsch synthesis in a tubular reactor. Latin Am Appl Res 2006;36:141.

52. Fernandes FA, Teles UM. Modeling and optimization of FischerTropsch products hydrocracking. Fuel Process Technol 2007;88:207.

53. Pellegrini L, Locatelli S, Rasella S, Bonomi S, Calemma V. Modeling of Fischer-Tropsch products hydrocracking. Chem Eng Sci 2004;59:4781.

54. Marvast MA, Sohrabi M, Zarrinpashneh S, Baghmisheh GH. Fischer-Tropsch synthesis: modeling and performance study for Fe-HZSM5 bifunctional catalyst. Chem Eng Technol 2005;28:78.

55. Khadzhiev SN, Lyadov AS, Krylova MV, Krylova AY. FischerTropsch synthesis in a three-phase system with iron catalyst nanoparticles. Petroleum Chem 2011;51:24.

56. Rahimpour MR, Ghorbani A, Asiaee A, Shariati A. Conversion of refinery natural purge gases to liquid hydrocarbons in GTL loop with hydrogen-permselective membranes: an alternative to gas flaring. J Nat Gas Sci Eng 2011;3:461.

57. Davis WL. Fluidized bed reactor. Google patents, 1980.

58. Hartman $M$, Svoboda $K$, Pohořelý $M$, Šyc $M$, Jeremiáš $M$. Attrition of dolomitic lime in a fluidized-bed reactor at high temperatures. Chem Pap 2013;67:164.

59. Kunii D, Levenspiel O. Fluidization engineering. Boston, MA: Butterworth-Heinemann, 1991.

60. Fernandes FA, Sousa EM. Fischer-Tropsch synthesis product grade optimization in a fluidized bed reactor. AIChE J 2006;52:2844.

61. Fernandes FA. Modeling and product grade optimization of Fischer-Tropsch synthesis in a slurry reactor. Ind Eng Chem Res 2006;45:1047.

62. Mohammad Kazemeini RM, Fattahi M. Modelling of FischerTropsch synthesis in a fluidized bed reactor. Advanced Mater Res 2012;586:274.

63. do Sacramento EM, Carvalho PC, de Lima LC, Veziroglu TN. Feasibility study for the transition towards a hydrogen economy: a case study in Brazil. Energy Policy 2013;62:3.

64. Wang G, Wang Y-N, Yang J, Xu Y-Y, Bai L, Xiang H-W, et al. Modeling analysis of the Fischer-Tropsch synthesis in a stirred-tank slurry reactor. Ind Eng Chem Res 2004;43:2330.
65. Yang JH, Hur YG, Chun DH, Kim H-J, Lee H-T, Jung H, et al. Hydrodynamic effect of oxygenated byproduct during FischerTropsch synthesis in slurry bubble column. Chem Eng Process Process Intensification 2013;66:27.

66. De Swart JW. Selection, design and scale up of the FischerTropsch reactor. Fuel Energy Abstr 1997;38:393.

67. Deckwer WD, Serpemen Y, Ralek M, Schmidt B. Modeling the Fischer-Tropsch synthesis in the slurry phase. Ind Eng Chem Process Des Dev 1982;21:231.

68. Wang Y, Fan W, Liu Y, Zeng Z, Hao X, Chang M, et al. Modeling of the Fischer-Tropsch synthesis in slurry bubble column reactors. Chem Eng Process Process Intensification 2008;47:222.

69. Iulianelli A, Ribeirinha P, Mendes A, Basile A. Methanol steam reforming for hydrogen generation via conventional and membrane reactors: a review. Renewable Sustainable Energy Rev 2014;29:355.

70. Westermann T, Melin T. Flow-through catalytic membrane reactors - principles and applications. Chem Eng Process Process Intensification 2009;48:17.

71. Rahimpour MR, Elekaei H. A comparative study of combination of Fischer-Tropsch synthesis reactors with hydrogenpermselective membrane in GTL technology. Fuel Process Technol 2009;90:747.

72. Rahimpour MR, Elekaei H. Optimization of a novel combination of fixed and fluidized-bed hydrogen-permselective membrane reactors for Fischer-Tropsch synthesis in GTL technology. Chem Eng J 2009;152:543.

73. Rahimpour MR, Mirvakili A, Paymooni K. Differential evolution (de) strategy for optimization of hydrogen production and utilization in a thermally coupled membrane reactor for decalin dehydrogenation and Fischer-Tropsch synthesis in GTL technology. Int J Hydrogen Energy 2011;36:4917.

74. Rahimpour MR, Forghani AA, Mostafazadeh AK, Shariati A. $\underline{A}$ comparison of co-current and counter-current modes of operation for a novel hydrogen-permselective membrane dualtype FTS reactor in GTL technology. Fuel Process Technol 2010;91:33.

75. Forghani AA, Elekaei H, Rahimpour MR. Enhancement of gasoline production in a novel hydrogen-permselective membrane reactor in Fischer-Tropsch synthesis of GTL technology. Int J Hydrogen Energy 2009;34:3965.

76. Rahimpour MR, Jokar SM, Jamshidnejad Z. A novel slurry bubble column membrane reactor concept for Fischer-Tropsch synthesis in GTL technology. Chem Eng Res Des 2012;90:383.

77. Anxionnaz Z, Cabassud M, Gourdon C, Tochon P. Heat exchanger/reactors (hex reactors): concepts, technologies: state-of-the-art. Chem Eng Process Process Intensification 2008;47:2029.

78. Rahimpour MR, Khademi MH, Bahmanpour AM. A comparison of conventional and optimized thermally coupled reactors for Fischer-Tropsch synthesis in GTL technology. Chem Eng Sci 2010;65:6206.

79. Bayat M, Rahimpour MR. Simultaneous hydrogen injection and in-situ $\mathrm{H}_{2} \mathrm{O}$ removal in a novel thermally coupled two-membrane reactor concept for Fischer-Tropsch synthesis in GTL technology. J Nat Gas Sci Eng 2012;9:73.

80. Rahimpour MR, Mirvakili A, Paymooni K, Moghtaderi B. A comparative study between a fluidized-bed and a fixed-bed water perm-selective membrane reactor with in situ $\mathrm{H}_{2} \mathrm{O}$ 
removal for Fischer-Tropsch synthesis of GTL technology. Nat Gas Sci Eng 2011;3:484.

81. Rahimpour MR, Mirvakili A, Paymooni K. Hydrogen as an energy carrier: a comparative study between decalin and cyclohexane in thermally coupled membrane reactors in gas-to-liquid technology. Int J Hydrogen Energy 2011;36:6970.
82. Rahimpour MR, Mirvakili A, Paymooni K. A novel water permselective membrane dual-type reactor concept for Fischer-Tropsch synthesis of GTL (gas to liquid) technology. Energy 2011;36:1223.

83. Rahimpour MR, Mirvakili A, Paymooni K. Simultaneous hydrogen production and utilization via coupling of FischerTropsch synthesis and decalin dehydrogenation reactions in GTL technology. Int J Hydrogen Energy 2011;36:2992. 